\title{
Dobles exequias y circulación de reliquias en el Calcolítico Inicial de la Cuenca del Duero: Sobre las inhumaciones parciales del "recinto de fosos" de Santa Cruz III (Cabezón de Pisuerga, Valladolid)
}

\section{Secondary burials and circulation of relics in the Duero Basin Early Copper Age: On the partial burials of the "causewayed enclosure" of Santa Cruz III (Cabezón de Pisuerga, Valladolid)}

\author{
Germán Delibes de Castro , Ángel Esparza Arroyo², Javier Velasco Vázquez³, Marcos García García ${ }^{1}$, \\ Angélica Santa Cruz del Barrio1, y Jesús Misiego Tejeda4.
}

Recibido: 27-03-2019

Aceptado: 24-09-2019

\begin{abstract}
Resumen
El fenómeno de las "dobles exequias", tempranamente teorizado por R. Hertz (1907), ha servido como marco interpretativo en numerosos estudios de Antropología y Arqueología funerarias. En este trabajo se ensaya su aplicación al Calcolítico Inicial de la Cuenca de Duero (ca. 3000-2400 cal AC), utilizando como punto de partida el estudio bioarqueológico de los restos de dos inhumaciones parciales localizadas en sendos hoyos del recinto de fosos de Santa Cruz III, en Cabezón de Pisuerga. En un intento de trascender este limitado caso de estudio, se pasa revista a otros enterramientos de este tipo documentados en el mismo ámbito cultural. A partir de la descripción de casos — sin recurrir a la analogía etnográfica para explicar cada hecho particular-, se propone una interpretación de conjunto fundamentada en aquella teoría, integrando las heterogéneas manifestaciones conocidas en una compleja secuencia que trata de dar cuenta de la extrema variabilidad (desde sepulturas primarias a huesos-reliquia) que se viene observando en el registro arqueológico.
\end{abstract}

Palabras clave:

Península Ibérica; Calcolítico; Bioarqueología; Prácticas mortuorias; Segundas exequias; Reliquias.

\begin{abstract}
'Double burials' concept, early theorized by R. Hertz (1907), has been a frequent interpreting framework in many studies of Anthropology and Archaeology of Death. This paper applies Hertz's approach to the funerary rituals of the Early Copper Age in Duero Basin (c. 3000-2400 cal BC), starting from a bioarchaeological study of the partial burials located in two pits of the Santa Cruz III causewayed enclosure (Cabezón de Pisuerga, province of Valladolid, Spain). Looking for a broader picture, the heterogeneous funerary practices of the area during Early Copper Age (from primary burials to relics) are reviewed. From their description, a general reading based on 'double burials' theory is proposed, without using the ethnographic analogy for a direct explanation of each particular event.
\end{abstract}

Key words:

Iberian Peninsula; Copper Age; Bioarchaeology; Mortuary practices; Secondary burials; Relics.

\footnotetext{
1 Dpto. de Prehistoria, Arqueología, CC.TT.Historiográficas y Antropología Social. Universidad de Valladolid, email: delibes@fyl.uva.es; https://orcid.org/0000-0002-5553-6414.

2 GIR PrehUSAL. Dpto. de Prehistoria, Hª Antigua y Arqueología. Universidad de Salamanca, esparza@usal.es, http://orcid.org/ 0000-0002-9139-0774.

3 Dpto. de Ciencias Históricas. Universidad de las Palmas de Gran Canaria, javier.velasco@ulpgc.es; https://orcid.org/0000-00030339-3500.

4 STRATO Arqueología. Valladolid.
} 


\section{INTRODUCCIÓN}

El Calcolítico representa un punto de inflexión en la trayectoria de la Prehistoria reciente de la Cuenca del Duero: con el acceso al metal crecieron las posibilidades de renovar la tecnología; en consonancia con los principios de la Revolución de los Productos Derivados o Secundarios, se experimentó un impulso económico sobresaliente; y a resultas de todo ello se disparó la demografía, se intensificó el proceso de sedentarización, los poblados aumentaron de tamaño y se tendió a dotarlos de infraestructuras de alto coste, como los "recintos de fosos" (Delibes, 2014; Villalobos, 2016a; García Barrios, 2006). Ante tantos y tan relevantes cambios, nada puede sorprender que también sufrieran mudanza las creencias y que se asistiera por entonces al declive de los dólmenes y a la implantación de una fórmula funeraria alternativa, de inhumaciones en fosa, con la que se ponía fin a la tradición de la tumba dolménica comunitaria (Fabián, 1995).

Sin embargo, como ya hemos apuntado otras veces (Delibes et al., e.p.), aunque sea legítimo afirmar que las "tumbas en fosa" fueron, desde una perspectiva arqueológica, la manifestación funeraria por excelencia de los nuevos tiempos, lo cierto es que entre ellas se registran importantes diferencias reveladoras de la complejidad del concepto: porque siendo la mayoría fosas individuales, las hay también múltiples; porque mientras en muchas ocasiones los cadáveres se encuentran perfectamente colocados en el fondo de los hoyos, en justa correspondencia con la solemnidad esperada de una ceremonia de despedida, en otras - tal vez por tratarse de tumbas de relegación - se dirían despectivamente tirados en ellos; porque no se observa una pauta clara en cuanto a postura y orientación de los cuerpos; o, sencillamente, por las dudas habidas sobre si existió costumbre o no de realizar ofrendas a los muertos (Esparza et al., 2008). A esa amplia casuística habría que añadir todavía el reconocimiento de dos clases de enterramientos según las inhumaciones sean completas y primarias o se reduzcan a restos parciales sin conexión anatómica, circunstancia esta atribuible al traslado de huesos desarticulados desde una sepultura (?) provisional.

¿Cómo podría entenderse un panorama tan complejo, que cabría tildarse incluso de caótico? Desde luego, algunas de las manifestaciones observadas pudieran justificarse buscando cualquier analogía etnográfica directa, pero en el presente trabajo, con motivo de dar a conocer dos enterramientos secundarios descubiertos modernamente en el yacimiento vallisoletano de Santa Cruz III, se aborda un estudio de todo el conjunto en relación con una teoría ya clásica en los ámbitos de la Sociología y la Antropología de la muerte: la de las dobles exequias propuesta por R. Hertz $(1907,1990)$ a partir de sus investigaciones en Borneo. Sostiene este autor que, frente al muy extendido tipo de enterramiento inmediato, definitivo, esta modalidad de los funerales dobles comprende un primer momento, con alguna forma de deposición transitoria - sepultura temporal, pudridero, expositor, etc - y otro - "secondes funerailles" - en el que se produce el enterramiento definitivo, de carácter secundario, de unos restos más o menos completos, desarticulados y descarnados. En resumen: si en el primer momento se enterró (guardó, expuso, etc.) un cuerpo, el segundo se caracterizaría por algunos huesos secos. Relacionadas con la propia transformación del cadáver, serían las etapas de una secuencia que viene a coincidir con los estadios propuestos por Van Gennep (2013).

El trabajo arranca, pues, con el estudio de las novedades documentadas en Santa Cruz III, para elevarse después al conjunto de enterramientos de la Edad del Cobre de la Cuenca del Duero, los cuales, además de ejemplificar un fenómeno de dobles exequias, en cierto modo emparentado con los "rituales de los antepasados" característicos del megalitismo, constituyen el germen de prácticas mortuorias fuertemente implantadas en el horizonte Cogotas I de la Edad del Bronce. Finalmente, aunque se trate de algo marginal dentro del presente trabajo, tampoco se pasa totalmente por alto la asociación de las sepulturas de Santa Cruz a un "recinto de fosos", hecho sin precedentes hasta ahora en Castilla y León.

\section{El Yacimiento de Santa CRUZ III y LOS NUEVOS DOCUMENTOS FUNERARIOS}

\subsection{Ubicación y descripción}

Santa Cruz III, a $8 \mathrm{~km}$ al Norte de Valladolid, se localiza en el exterior de un pronunciado meandro del Pisuerga, en su margen derecha, formando parte de una amplia llanura aluvial flanqueada por los páramos de Torozos y Cerrato. Su posición, que responde a las coordenadas UTM X=360.377,69 $\mathrm{Y}=4.620 .684,29$ (datum ETRS 89 UTM 30), apenas destaca por encima del fondo del valle y de ahí su nombre - es el tercer yacimiento localizado en el caserío de Santa Cruz, una finca a $2 \mathrm{~km}$ al Este de Cabezón por la que, además del Pisuerga, 


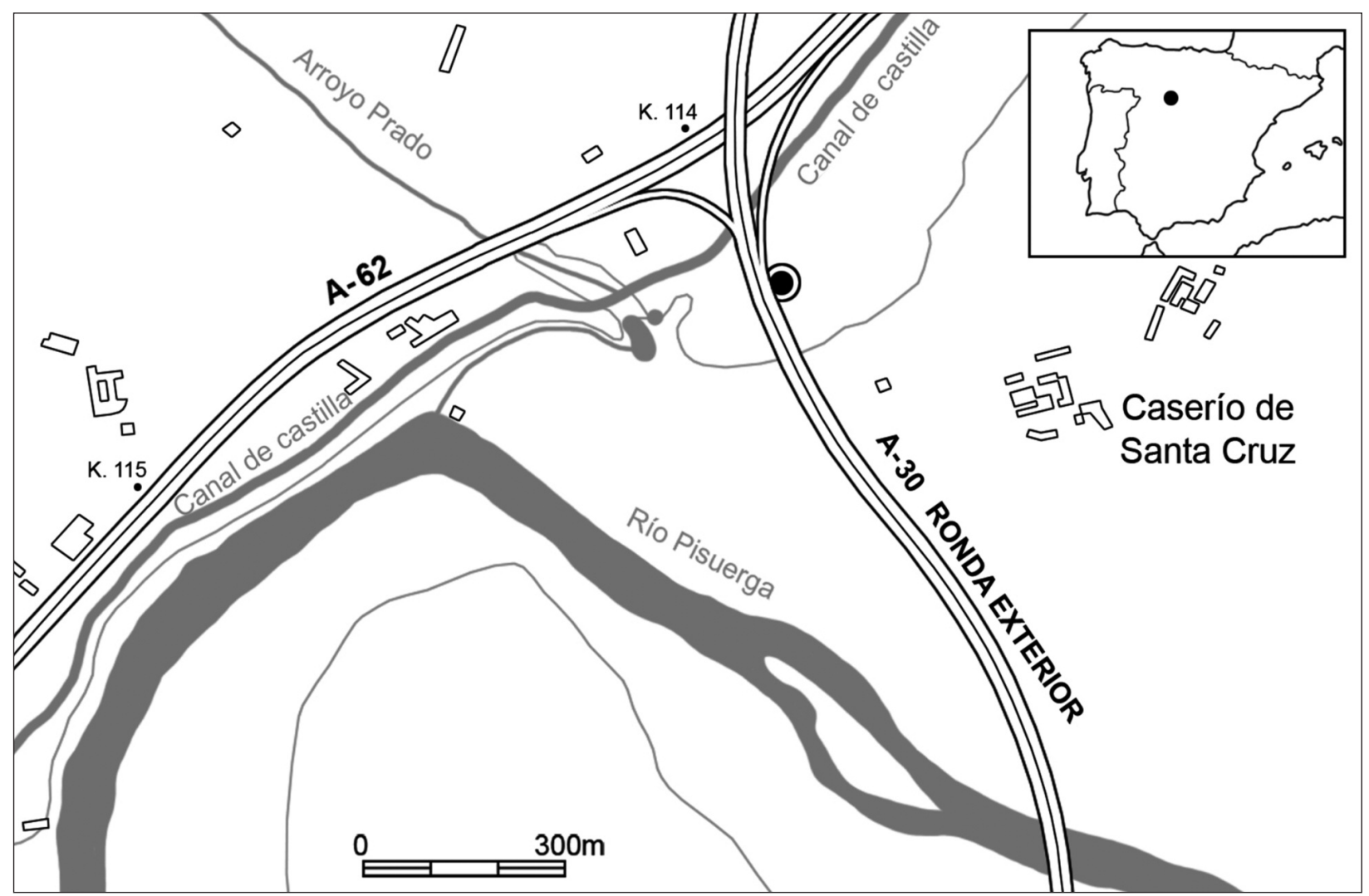

Figura 1. Localización del yacimiento de Santa Cruz III (Cabezón de Pisuerga, Valladolid).

discurren el Canal de Castilla y el arroyo del Prado (fig. 1). Identificado en 2006 durante el seguimiento de las obras de la Ronda Exterior Este de Valladolid, el yacimiento fue objeto de excavación arqueológica tres años después por la empresa Strato S.L. con el resultado de la exhumación de un amplio tramo de foso (más de 70 metros lineales) y de 82 hoyos, todos ellos con materiales encuadrables en el horizonte "Las Pozas-Los Cercados" de la plenitud de la Edad del Cobre regional (fig. 2). Con posterioridad, el análisis de una fotografía de 'falso color' del Plan Nacional de Ortofotografía Aérea (PNOA), que incluye una banda de infrarrojos, ha permitido reconocer la planta completa del yacimiento: un pequeño recinto de fosos ovalado con al menos una entrada, similar en su diseño a muchos de los enclosures calcolíticos del valle medio del Duero (Delibes et al., 2014).

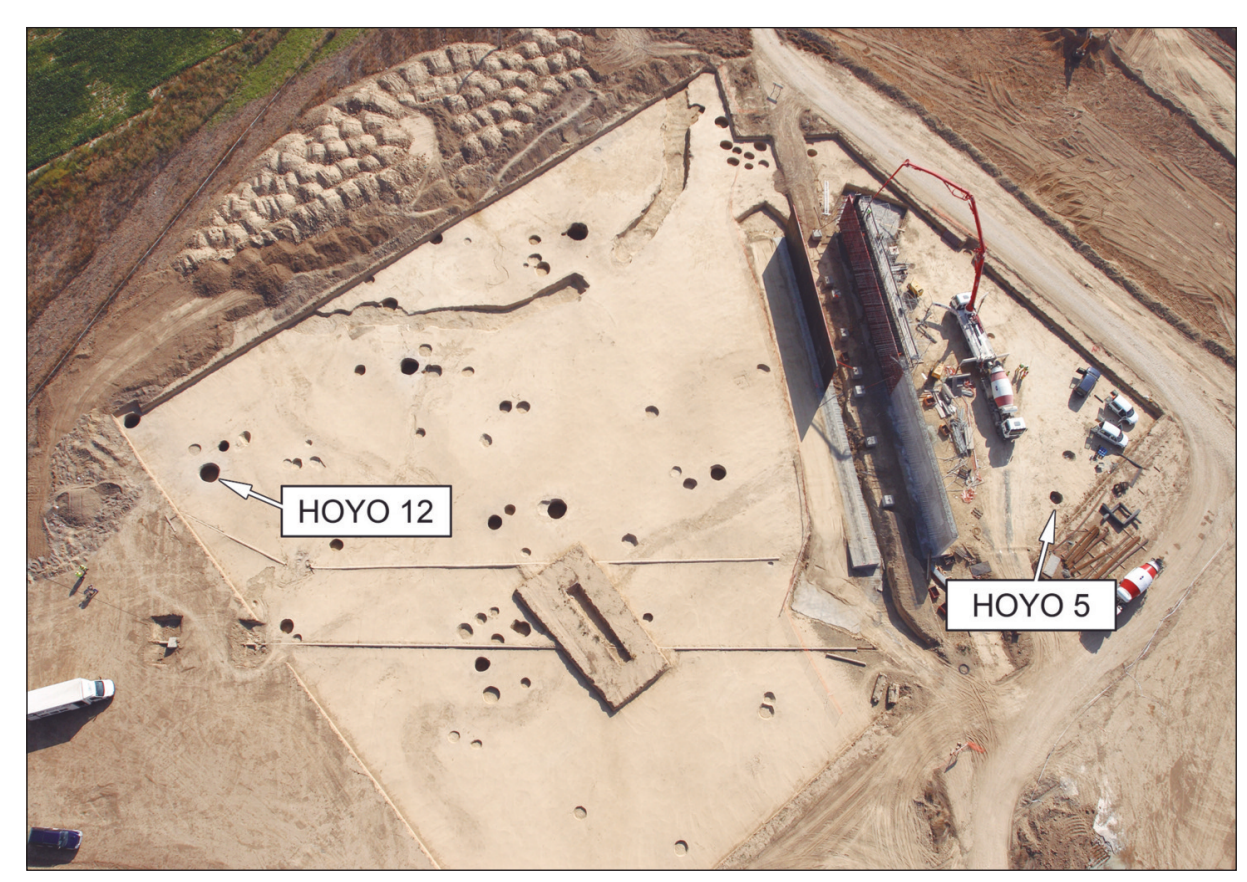

Figura 2. Vista general del recinto de fosos (arriba) y del campo de hoyos de Santa Cruz. III durante el proceso de excavación. 


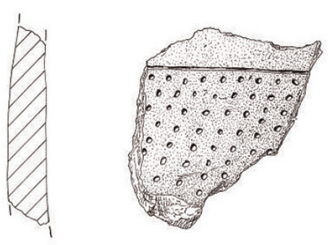

2009/11/46

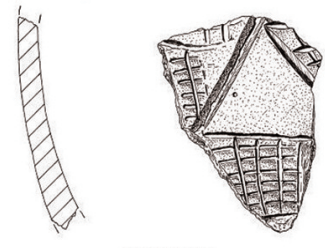

$2009 / 11 / 670$

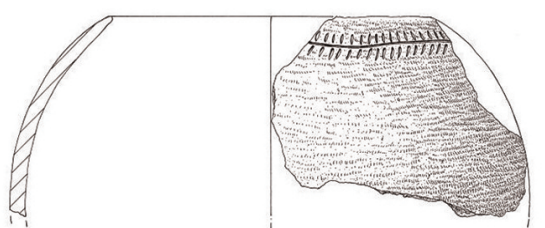

$2009 / 11 / 344$
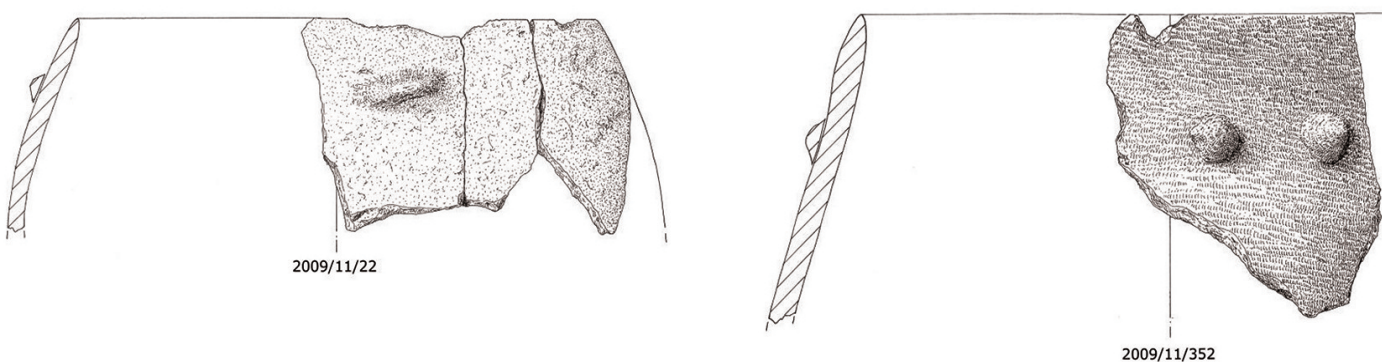

$2009 / 11 / 352$
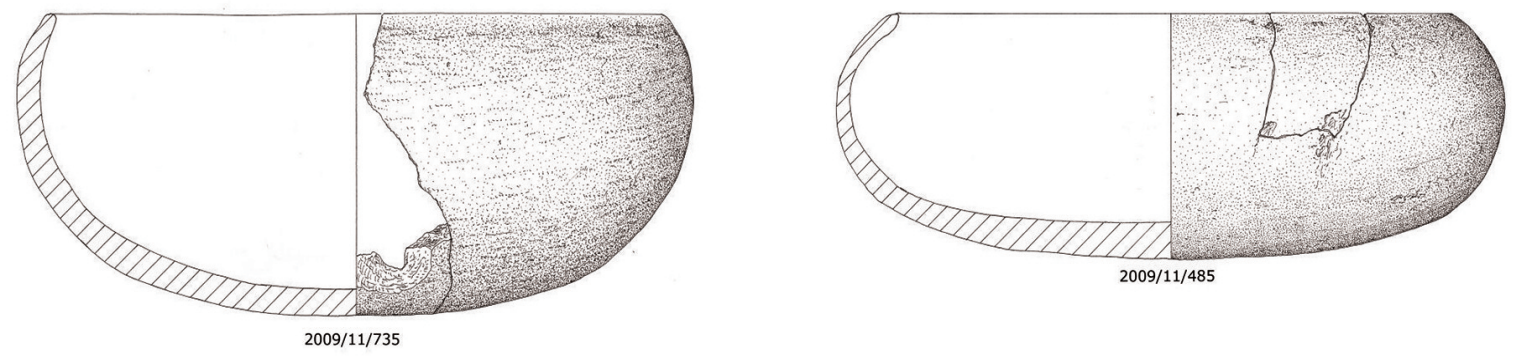

${ }^{0}={ }^{5 \mathrm{~cm}}$
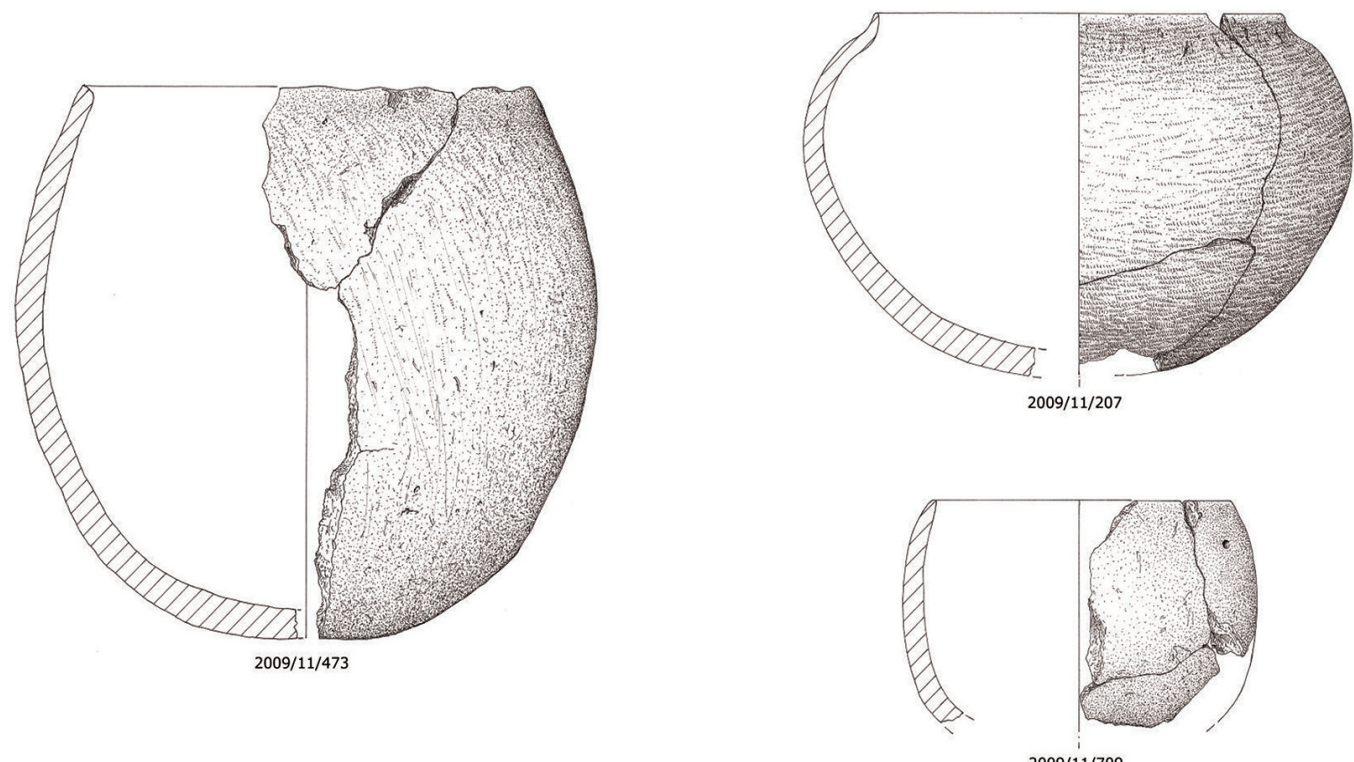

$2009 / 11 / 709$

Figura 3. Muestra de materiales calcolíticos precampaniformes de Santa Cruz III. 
Al igual que en otros recintos excavados, como el vallisoletano de El Casetón de la Era (Delibes et al., 2016), el foso de Santa Cruz III muestra un relleno de aportes antrópicos (cenizas, barro de construcción, restos de objetos de uso cotidiano y huesos de animales), a primera vista muy similar al de la generalidad de los "hoyos" del mismo yacimiento. Sin embargo, dos de estos, los $n^{\circ}$ 5 y 12 , ofrecen la particularidad de incluir restos humanos.

\subsection{Contexto y materiales}

Estos dos últimos hoyos, localizados al exterior de la línea perimetral del foso y demasiado aislados y distantes entre sí (más de 70 m) para pensar que formaran parte de una misma "área funeraria", son de grandes dimensiones aunque no pueda precisarse su profundidad original por haber sido todo el yacimiento decapado mecánicamente hasta $-50 \mathrm{~cm}$. A ese nivel se apreciaban en el suelo los manchones oscuros de sus bocas, un círculo de $160 \mathrm{~cm}$ de diámetro en el hoyo $\mathrm{n}^{\circ} 5$ y un óvalo de más de dos metros $(285$ x $215 \mathrm{~cm})$ en el otro. El primero, de $88 \mathrm{~cm}$ de profundidad relativa, tiene sección cuenquiforme, mientras que el $\mathrm{n}^{\circ} 12$, con un desarrollo mucho más vertical $(145 \mathrm{~cm})$, adopta forma globular. Ambos presentaban un relleno "no estratificado", que en la memoria de los trabajos se define como "de tierra cenicienta de descomposición de restos orgánicos" (fig. 3) ${ }^{5}$.

El único resto humano del hoyo 4 es una calota craneal hallada junto a una muestra abundante de huesos de animales que, de acuerdo con la Memoria citada, comprendía "costillas, astrágalo, calcáneo, tibia, vértebras, pelvis, falange y otros de bóvido; asta, costillas, tibia, calcáneo y otros de cérvido; molares de ovicáprido; mandíbula de suido y otros indeterminados". Y la situación, en cuanto a abundancia de fauna, se repite en el hoyo 12, con "mandíbula, astas, costillas, vértebras, metápodos, tarsos,

astrágalos, falanges, escápulas, radio, fémur, húmero, cúbitos, tibias y otros de bóvido; astas, mandíbulas (de adulto e infantil), costillas, metápodos y otros de cérvido; cráneo, astas, costillas, metápodos, astrágalos, mandíbulas, escápulas, vértebras, húmero, cúbito, pelvis, calcáneos y otros de ovicáprido pequeño y adulto; cráneos, abundantes mandíbulas, costillas, vértebras, metápodos y otros de cánido infantil y adulto; y muchos otros indeterminados", todos ellos localizados en cotas más altas que "los restos incompletos de un esqueleto humano sin conexión anatómica" que yacen a diferentes cotas en la parte inferior del hoyo.

También los elementos de cultura material (cerámicas, pellas de manteado de barro y restos de talla de sílex) son abundantes: 382 piezas en el hoyo 5 y 598 en el 12. Atendiendo al carácter fragmentario y anodino de la mayoría podría pensarse en una llegada accidental de los mismos a las fosas, junto a los rellenos de tierra; sin embargo su abundancia y a veces su entidad - en el hoyo 5, dos punzones de hueso, parte de una punta de flecha de sílex y una

\footnotetext{
5 Los datos proceden de la Memoria de Strato, Trabajos Arqueológicos necesarios en la construcción de la Autovía A-30, Ronda Exterior Este de Valladolid. Tramo: Autovía del Duero (A-11) - Autovía de Castilla (A-62). Provincia de Valladolid. Excavación Arqueológica en Área en el yacimiento de "Santa Cruz III" (Cabezón de Pisuerga, Valladolid), depositada en el Servicio Territorial de Cultura de la Junta de Castilla y León de Valladolid. .

6 Son los únicos conservados; los restantes fueron reenterrados en el propio yacimiento, lo que impide tanto describirlos en detalle como conocer su grado de fragmentación y rodamiento.
} 
afiladera de cuarcita; y en el 12 un punzón y una espátula de hueso más un dudoso perforador de sílex, todos ellos en el Museo Arqueológico de Valladolid ${ }^{6}$ - obliga a ser cautos a la hora de utilizar el siempre resbaladizo término de "basura" (Moore, 1982: 76). Gracias a tales objetos y a los perfiles en globo de lámpara y de carena baja de las cerámicas, es posible deducir la cronología calcolítica de los hoyos 5 y 12, no otra que la que merece todo el yacimiento de Santa Cruz III a juzgar por una datación de TL obtenida en el foso $2067+34$ a.C. - y por la presencia de fósiles-guía tan típicos de ese momento como las puntas de flecha y las láminas de sílex, las hachas pulimentadas, los punzones de cobre o las cerámicas decoradas con triángulos rellenos de puntos impresos o con acanalados horizontales (fig. 3).

\subsection{Los restos humanos}

a) El individuo del hoyo 12: Los restos esqueléticos corresponden en este caso a un individuo adulto, posiblemente de sexo masculino. El aspecto de los huesos es robusto y su estado de conservación bueno a pesar tanto de las alteraciones de origen hídrico y de las ocasionadas por la acción de pequeñas raíces, como de algunas fracturas y erosiones muy localizadas.

Cabe destacar igualmente que la representación esquelética es parcial, sobre todo con tipos óseos correspondientes a la mitad superior del cuerpo (fig. 5), mientras que del esqueleto apendicular solo se registran los

Figura 5. Santa Cruz III: representación anatómica del individuo del hoyo $n^{o} 12$. radios de ambos lados y metatarsos y falanges del pie izquierdo. A juzgar por el estado del material esquelético no parece que puedan atribuirse las citadas ausencias a un fenómeno de conservación diferencial. La presencia de huesos frágiles como las costillas, o más susceptibles a la degradación por su alto contenido en hueso esponjoso, como las vértebras, es reveladora de que la parcialidad del conjunto esquelético responde a un proceso de selección antrópico. El tipo de huesos presentes en el depósito, su aspecto

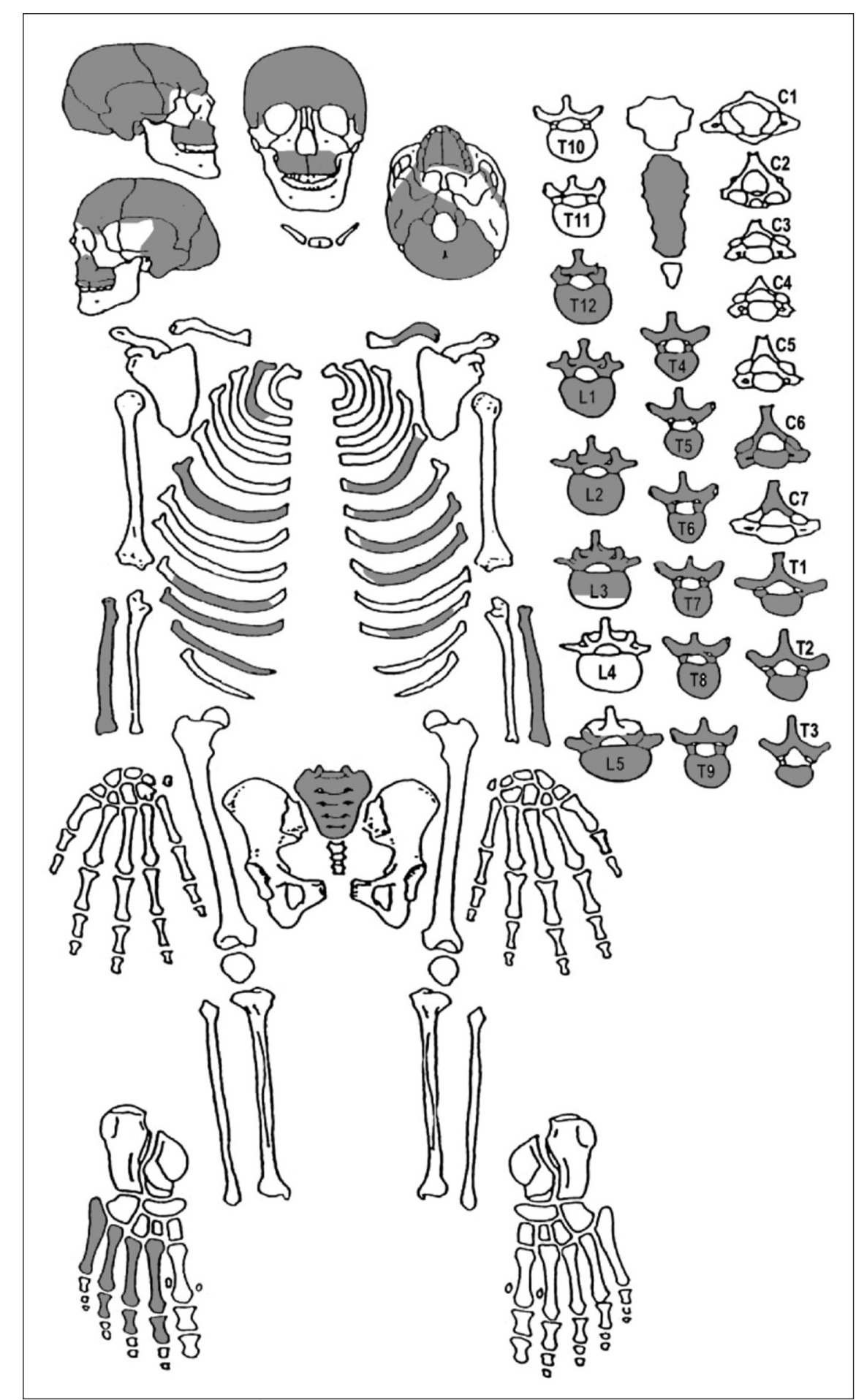



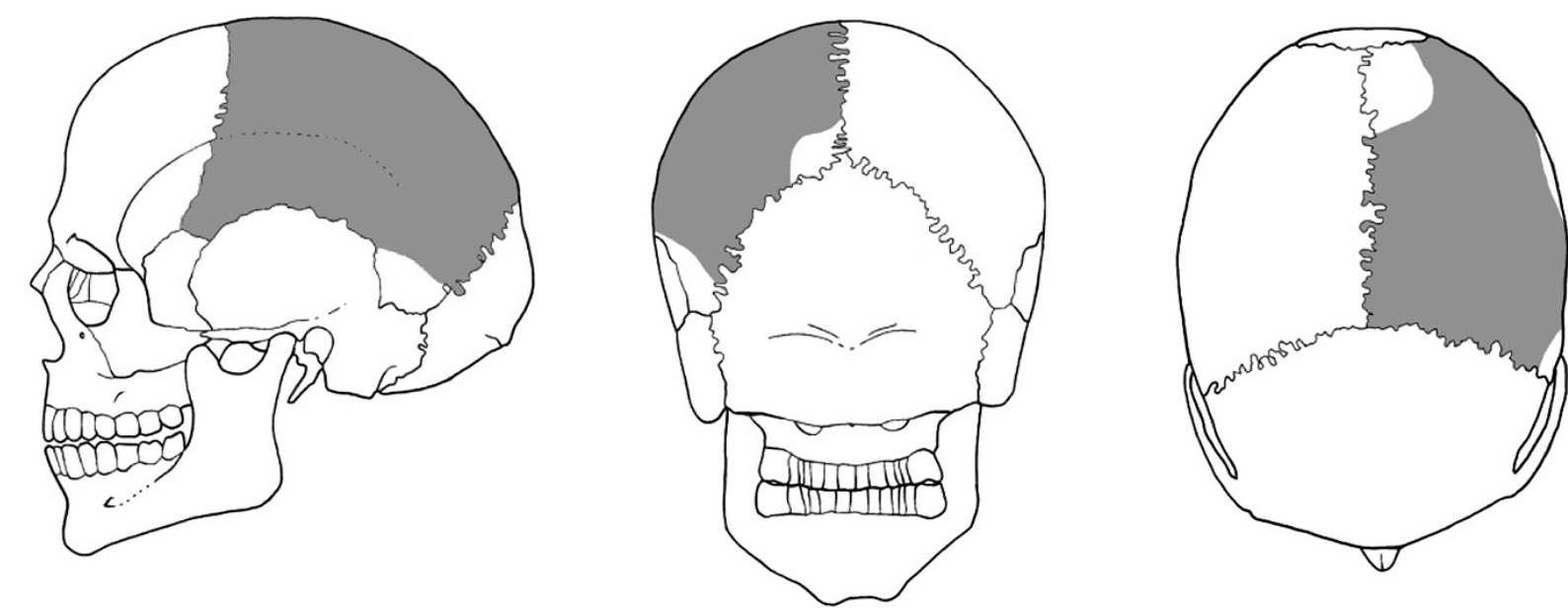

Figura 6. Santa Cruz III: representación anatómica-únicamente un parietal-del individuo del hoyo $n^{\circ} 5$.

y robustez permiten defender, además, que todos ellos corresponden a un único individuo.

Para la determinación del sexo se ha tenido en cuenta la morfología y robustez del cráneo, siguiendo tanto los criterios compilados por Buikstra y Ubelaker (1994) como los establecidos por Campillo y Subira (2004). De acuerdo asimismo con estos autores, la determinación de la edad se basó en la observación de la maduración ósea, grado de desgaste de los molares y cambios en la extremidad esternal de las costillas. A partir de tales variables deducimos que los restos pertenecen a un varón fallecido entre los 25 y los 35 años: hacia los 24-28 según los rasgos del extremo esternal de las costillas y superada la treintena de acuerdo con la presencia de ciertos procesos degenerativos. Determinados rasgos del cráneo plantearían dudas sobre la masculinidad del sujeto, pero tanto su robustez como la morfología del esqueleto poscraneal nos reafirman en el diagnóstico.

Para el cálculo de la estatura solo se dispone de los radios, deduciéndose de su longitud que el sujeto midió entre 1,70 y 1,72 m. Es bastante evidente, por otro lado, la asimetría del radio derecho con respecto al izquierdo, siendo el primero bastante más robusto y con mayor desarrollo de las inserciones musculares, aparte de mostrar lesiones osteoartrósicas (OA) en la extremidad distal. Asimismo hay huellas ostensibles de procesos degenerativos en la superficie caudal de la quinta lumbar, con la presencia de osteofitos en sus márgenes anteriores que se repiten en la tercera asociados a modificaciones de la superficie articular en sus apófisis laterales. Y también hay presencia de alteraciones OA en la articulación costovertebral de una de las costillas izquierdas (de posición más caudal).

Desde el punto de vista paleopatológico es igualmente destacable la presencia de una espondilólisis bilateral o defecto en la pars interarticularis de L5 o quinta vértebra lumbar. La etiología de la espondilólisis está sujeta a una cierta controversia, atribuyéndose su origen bien a un componente genético, bien a procesos traumáticos asociados a una intensa actividad física (hiperflexión de la región lumbar, por ejemplo). En todo caso, son cada vez más los trabajos que se hacen eco de la complejidad de los factores que intervienen en su origen, no necesariamente excluyentes entre sí (p.ej., Waldron 2008). Todo ello impide asegurar que en este caso se debiera - al menos en exclusiva - a una fractura por sobrecarga, si bien la robustez del sujeto invita a tener presente tal posibilidad.

En lo que respecta a la antropología dental, solo conserva la arcada maxilar, en la que se registra un moderado desgaste de las superficies oclusales de los molares, sin que se observen lesiones cariosas ni pérdidas. Tampoco se detectan depósitos de sarro, aunque es probable que en buena parte de los dientes se hayan desprendido a raíz de los procesos posdeposicionales. En este sentido, hay un evidente retroceso del soporte óseo alveolar (en algún caso de hasta $6 \mathrm{~mm}$ ) que puede atribuirse a la presencia de tártaro en vida de este sujeto, pues no se aprecian a simple vista otras anomalías que lo expliquen. Únicamente se detecta una línea hipoplásica en la corona del canino izquierdo, lo que parece indicativo de que el individuo no sufrió severos procesos de estrés a lo largo de su infancia. 
b) El individuo del hoyo 5: Está representado únicamente por un parietal izquierdo completo, que corresponde también a un adulto. Las pequeñas porciones perdidas (un fragmento medial y otro lateral) muestran fracturas antiguas, por lo que con bastante seguridad no se desprendieron dentro del hoyo. Presenta en el interior algunas concreciones calcáreas y porosidad atribuible a procesos tafonómicos, mientras que en el exterior se aprecia pérdida de tejido óseo debida a la humedad y a la acción de pequeñas raíces (fig. 6).

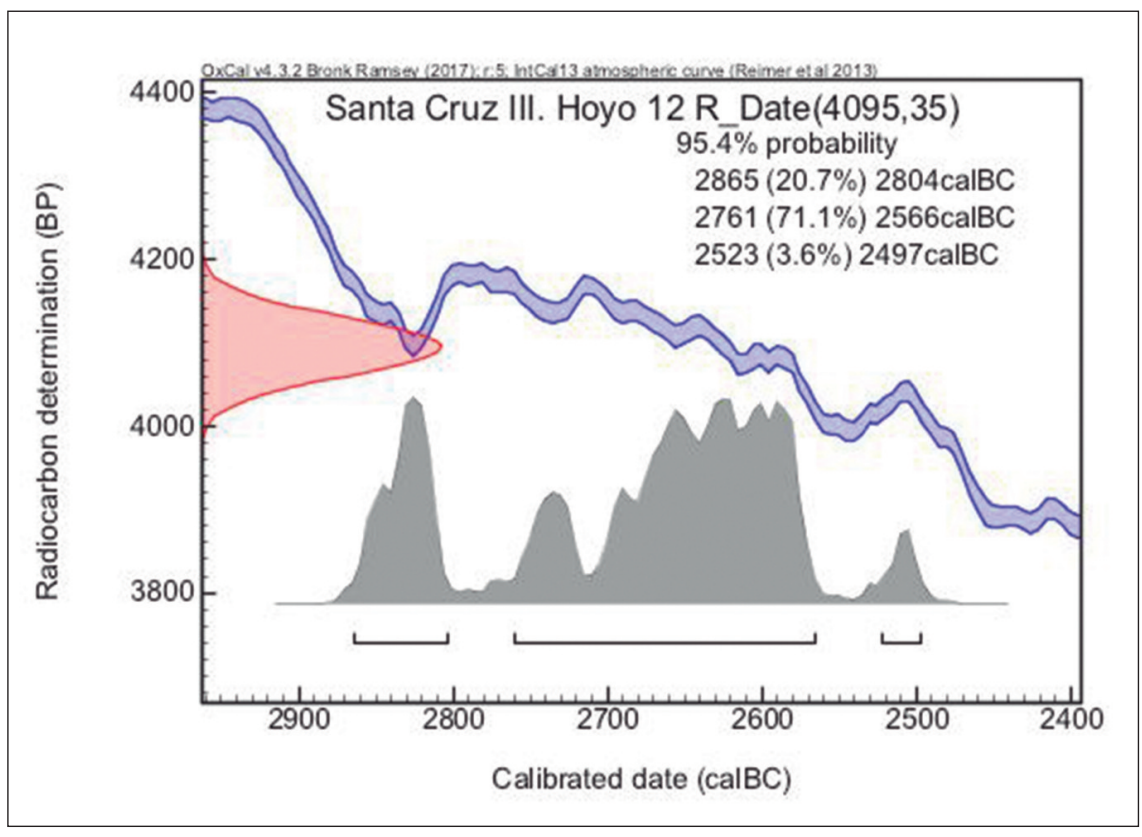

Figura 7. Datación radiocarbónica del esqueleto del hoyo $n^{\circ} 12$.

No existen suficientes elementos para diagnosticar el sexo del individuo y, en cuanto a la edad, solo ha podido estimarse a partir del grado de obliteración de las suturas craneales, que sugieren un fallecimiento entre los 20 y los 35 años.

\subsection{Datación radiométrica}

Enviamos muestra de una de las costillas humanas del hoyo número 12 al Laboratorio de Radiocarbono de Poznan (Poz-49172) para su datación mediante la técnica AMS con el siguiente resultado: 4095 35 BP (García García, 2017: 27). La calibración a $2 \sigma(95,4 \%$ de probabilidad) realizada con el programa OxCal v.4.2 y la curva IntCal 13 proporciona los siguientes intervalos: 2865 2804 cal BC (20,7\%); 2761-2566 cal BC $(71,1 \%)$; 2523-2497 (3,6\%) (fig. 7).

\section{Discusión: UNa TEORÍA Y NUEVOS DATOS}

\subsection{El aparentemente canónico enterramiento individual en hoyo}

Las sepulturas en fosa localizadas dentro de los asentamientos, compartiendo espacio con estructuras de habitación y almacenaje, constituyen la expresión arqueológica por excelencia de las prácticas funerarias de los inicios de la Edad del Cobre en el sector central de la Submeseta Norte (Esparza et al., 2008: 30-33; Fabián y Blanco, 2012; Carmona et al., 2013; Delibes et al., e.p.) y, sin grandes diferencias, en los alrededores de Madrid (Aliaga, 2008; Díaz del Río et al., 1997). Enterramientos mayorita-

riamente individuales, frente a aquellos otros múltiples (Andrés, 1990) que por su excepcionalidad suelen incluirse en la categoría de "sepulturas de catástrofe" (Aliaga, 2012: 15), caso de la fosa $n^{\circ} 1$ del Cerro de La Cabeza, en Ávila, con los cuerpos de seis individuos muy probablemente abatidos en el transcurso de un mismo conflicto (Fabián y Blanco, 2012: 113). Tres circunstancias contribuyen a reforzar la personalidad de estas sepulturas en fosa que nada raramente aprovechan viejos silos: se trata de la única modalidad funeraria calcolítica conocida en el centro de la Cuenca del Duero; representan una clara ruptura respecto a los mausoleos megalíticos previos; y marcan distancias también con el patrón de enterramiento colectivo en cueva de las comunidades coetáneas del reborde montañoso oriental de la Meseta.Además, en la bibliografía se ha ido deslizando la idea de que nuestras fosas acogen inhumaciones en el sentido más estricto de la palabra (Esparza et al., 2008: 31; Aliaga, 2008: 26), esto es, de acuerdo con la terminología clásica de Duday (1990), cadáveres descompuestos "en espacio colmatado" o encerrados en tierra, circunstancia que revelaría la intención de aislar definitivamente a los difuntos del mundo de los vivos y, en cierto modo, de ocultar la muerte (Barrett, 1990: 32; Moragón, 2012: 25-26). Una pauta funeraria, en suma, que remitiría a inhumaciones sobre todo individuales y a enterramientos primarios, es decir a rituales que, a diferencia de los escenificados en los osarios colectivos neolíticos, ponen el acento en un tratamiento 
singularizado del individuo (¿como reflejo de una sociedad cada vez menos igualitaria?) y en la renuncia a la manipulación de los despojos de los muertos tras el deceso.

Seguramente es esta, sin embargo, una visión excesivamente simplificadora. Por ejemplo, como habrá ocasión de ver más adelante, es muy discutible la condición primaria y sellada de todos los enterramientos, pues existen claros depósitos en dos tiempos y circulación de huesos. Y con la misma sinceridad es preciso reconocer lo exiguo del número de tumbas en fosa registradas, demasiado bajo sin duda para las expectativas demográficas de unas comunidades cuyos efectivos, a juzgar por las dimensiones y la duración de sus establecimientos (Díaz del Río, 2001; Delibes et al., 2016) y por el calado de sus más importantes infraestructuras (Villalobos, 2016b: 61), debieron de ser considerables. Todo invita a pensar, pues, como se ha aducido en otras ocasiones (Fabián y Blanco, 2012: 114-115; Carmona et al., 2013: 74), que la muestra manejada no es representativa de los hábitos sepulcrales de la época, con lo que muy posiblemente se esté incurriendo en el error de atribuir carácter normativo a lo que realmente es solo minoritario o marginal (Bocquentin et al., 2010: 167).

La presunción de que los restos de gran parte de los difuntos no se traducen en documentos arqueológicos palpables es un desafío general de la Prehistoria europea (Brun, 2004: 56; idem, 2007: 128) que podría obedecer a razones muy diversas: personas a las que se niega el funeral o a las que no es posible enterrar porque sus cuerpos resultan inaccesibles (Weiss-Krejci, 2012a: 283); cadáveres no momificados que sucumben fácilmente a la bioerosión (Parker-Pearson et al. 2005; Booth et al.2015); individuos a los que se aplica rituales funerarios evanescentes, que no generan una impronta duradera, etc. Un problema complejo y difícil de abordar, dada la escasa competencia mostrada por la Arqueología para descifrar los fundamentos de las prácticas funerarias menos convencionales, pero de cuya existencia - aunque no en nuestro caso, por déficit de información - siempre cabrá sospechar a través del reconocimiento en la población enterrada de "anomalías demográficas" incompatibles con un patrón de mortalidad natural (Sellier, 1996; Esparza et al., 2012a: 286-298; Fernández- Crespo y de la Rúa, 2015).

Pero nuestro actual propósito es analizar la problemática de las sepulturas de Santa Cruz III, que, frente a las más habituales con inhumaciones completas, como la del hoyo 197 de El Soto de
Tovilla, en Valladolid - esqueleto entero, cuidadosamente colocado en el centro de la fosa en posición fetal, reposando sobre el costado izquierdo, lastrado con piedras y acompañado, lo que no deja de ser excepcional, por una vasija cerámica completa (Esparza et al., 2008) - , responden a un comportamiento funerario diferente. Recuérdese, en efecto, cómo la fosa $\mathrm{n}^{\circ} 12$ reúne solo una treintena de huesos de la mitad superior del cuerpo de un varón adulto, todos ellos además desordenados y sin la menor conexión anatómica; y que la n ${ }^{\circ} 5$ es también un enterramiento parcial, aunque minimalista pues se reduce a un único parietal, el izquierdo, de un adulto de sexo indeterminado.

Son, por tanto, enterramientos parciales y además - puesto que nada permite deducir que se trata de restos in situ de inhumaciones primarias removidas ni de reducciones - enterramientos secundarios o en dos tiempos, que en lo físico suponen traslado de material esquelético, ya limpio, de una localización, la provisional, a otra (Kólar, 2012), y en lo espiritual y simbólico una forma de despedir al difunto muy distinta de la nuestra y de la que, en general, encarnan los enterramientos primarios: si en estos con la inhumación se da por concluido el funeral, en los secundarios el enterramiento del cadáver o su exposición en un pudridero sólo supone el inicio de un largo tránsito o rito de paso que marcará la duración del duelo de los parientes y que no culminará hasta que, transcurrido cierto tiempo, - variable según los casos, al menos tanto como dure la putrefacción - tengan lugar la recuperación de los huesos del muerto y sus exequias definitivas (Hertz, 1907, 1990; Van Gennep, 2013; Metcalf, 1981; Wilder, 2003; WeissKrejci, 2012a: 282-284). Un ritual que tal vez, como señalábamos antes, no constituyó la norma funeraria del Calcolítico de la Cuenca del Duero pero que tampoco sería justo considerar excepcional y menos todavía exclusivo de las fosas de Santa Cruz III, pues, como veremos a continuación, agrupados en tres categorías, se conocen bastantes otros casos de enterramientos parciales y de restos humanos aislados que, en general, riman bien con la idea de prácticas funerarias en varios tiempos.

\subsection{Fosas con restos esqueléticos parciales no articulados}

Es la situación registrada tanto en la inhumación del hoyo 103 de El Hornazo (Villimar, Burgos), con cráneo, dos peronés y varios huesos de los brazos de un individuo de 14-15 años (Carmona et al., 2013: 67), como en la fosa 12 de 
Santa Cruz III, también con cráneo pero acompañado de muy escasas piezas del esqueleto apendicular. En El Hornazo el descoyuntamiento de los huesos, deducido de su correspondencia a áreas anatómicas discontinuas, parece evidente; y en la documentación sobre Santa Cruz se insiste expresamente en el aislamiento del cráneo y en la "desconexión anatómica" de los demás restos. Muy parecidas reflexiones merecen los esqueletos de la fosa colectiva de El Tomillar (Bercial de Zapardiel, Ávila), dando lugar a la explicación, extrapolable a El Hornazo 103 y a Santa Cruz 12, de que se trata de enterramientos parciales y secundarios, es decir, de conjuntos de restos, entre los que raramente falta el cráneo, trasladados a lo largo del tiempo desde una sepultura o depósito anterior (Etxeberria, 1995: 54-55). Y situación similar, por último, se registra en una inhumación, la 112, del yacimiento de Las Matillas, en Madrid, con una representación esquelética también parcial y "depositada en un avanzado estado de descomposición" lo que explica la total desarticulación de sus huesos (Díaz del Río et al., 1997: 104).

\subsection{Hoyos con únicamente cráneos}

Son también tumbas parciales, pero de un único hueso tan representativo y lleno de simbolismo personal como el cráneo. Dos de ellos completamente aislados, que sirven de paralelos para la calvaria de la fosa $n^{\circ} 5$ de Santa Cruz III, yacían en el subsuelo de sendas cabañas de los poblados de La Viña de Esteban García, en Salamanca (Santonja, 1997: 74) y de Los Itueros, en Ávila (Fabián, 2006: 206). Pero el hallazgo más conocido es el de Los Cercados de Mucientes, en Valladolid, donde tres piezas, sin más complemento esquelético que una mandíbula, ocupaban el fondo de un hoyo enorme o de un foso. Corresponden a tres mujeres emparentadas por línea materna (Palomo, 2015: 331) y muestran los traumatismos que acabaron (¿ritualmente?) con sus vidas consecuencia de fuertes golpes, en dos de los casos ocasionados con un objeto punzante y en el otro con una cachiporra (García Barrios, 2007). Además, de una lectura contextual se deduce que los cráneos fueron depositados en el transcurso de una ceremonia en la que tuvieron también gran protagonismo el fuego y, sucesivamente, las cabezas de un perro y un cerdo, abundantes tajadas de carne, una tosca figurita de barro zoomorfa y varias vasijas cerámicas. Las dudas que en su día existieron sobre la posibilidad de que la mandíbula antes citada correspondiera a una cuarta persona se han disipado tras recientes análisis genéticos: pertenece, en efecto, a una de las tres mujeres inmoladas (Palomo et al., 2017).

Objetivamente, Mucientes es un enterramiento múltiple, de tres inhumaciones parciales que, a primera vista, se depositaron al tiempo. No está claro, sin embargo, si fueron inhumaciones primarias o secundarias: la presencia de cráneo y mandíbula de un mismo individuo parecería dar a entender lo primero, esto es, que la cabeza fue inhumada completa y aún con sus tejidos blandos, recién fallecida la persona a la que perteneció. Pero precisamente lo contrario, el hecho de no haberse documentado las mandíbulas ${ }^{7}$ de los otros dos cráneos en una excavación rigurosa, sugiere que estos llegaron al depósito ya esqueletizados, después de haber perdido piel y músculos en un sitio diferente. Otras opciones más sofisticadas, pero conciliadoras con ambas posturas y atentas a las voces que reclaman lecturas más complejas de los "campos de hoyos" (Blanco González, 2011; Sánchez Polo, 2012), serían que la fosa mucenteña hubiera recibido en la misma ceremonia una cabeza fresca y dos fósiles o que todas ellas fueran frescas pero que las dos últimas hubieran sido sometidas a una descarnación activa, no fruto de putrefacción natural sino inducida por el hombre (O’Shea, 1984: 25; Ubelaker, 2007: 42), de la que en todo caso no se conocen marcas. Sin duda estas dos últimas explicaciones pueden parecer demasiado rebuscadas, pero la realidad demuestra que en los reentierros o enterramientos secundarios no es raro que se reúnan restos de individuos de diferente antigüedad o transgeneracionales (por la pátina se sabe que algunos tuvieron un uso activo antes de ser depositados junto al resto), algo lleno de sentido en el marco del culto a los antepasados (Robb, 2013: 452-453). La situación es bien conocida en los escondrijos de cráneos multifásicos, pintados y repintados, del Neolítico Precerámico del Próximo Oriente (Kuijt, 2008: 175; Hughes, 2014: 80-81) y no otra cosa sugieren los enterramientos momificados británicos de la Edad del Bronce (Smith et al., 2016), sobre todo la insólita inhumación de Cladh Hallan, en las Hébridas, cuyo

\footnotetext{
7 Téngase en cuenta que la conexión atlanto-occipital es muy persistente, más incluso que la mandíbula (Duday et al., 2009), y que es complicado separar en fresco, tanto mandíbula como primera vértebra, sin la ayuda de herramientas.
} 
esqueleto fue enigmáticamente construido, como demuestra el radiocarbono, con huesos separados y momificados de tres individuos distintos y de diferentes épocas (Parker Pearson et al., 2005).

\subsection{Huesos sueltos y fragmentos de huesos acompañando a inhumaciones en principio completas: ¿depósitos accidentales?}

En el Cerro de la Cabeza se atestigua una nueva práctica mortuoria en la que intervienen restos parciales. En la fosa $\mathrm{n}^{\mathrm{o}} 2$, bajo el esqueleto completo de un varón de 40-45 años que, por la desarticulación de muchos de sus huesos, seguramente se enterró en estado de descomposición, se consignó la presencia de la falange proximal del dedo II de una mano derecha, con inserciones musculares llamativamente fuertes, que corresponde sin lugar a dudas a un segundo individuo (Fabián y Blanco, 2012: 107). Y en la n ${ }^{\circ} 4$, acompañando a los huesos de la cabeza "completamente aplastados" de otro varón de edad similar, también, a juzgar por la descolocación y parcialidad del esqueleto postcraneal, en posición secundaria, figuraba un fragmento de cráneo de otro sujeto distinto (Fabián y Blanco, 2012: 110). En ambos casos, la pequeñez de los restos y su discreta presencia - el fragmento de cráneo de la tumba 4 apenas se distinguía a primera vista de los aplastados correspondientes a la inhumación principal - plantean serias dudas sobre la voluntariedad de los depósitos.

Pero testimonio todavía más elocuente de tal tipo de prácticas procede de la fosa vallisoletana de Colmenares, en Portillo, pese a no haber sido objeto de una excavación cuidadosa (Herrán y Rojo, 1999). El estudio de los restos reveló que en su mayoría pertenecían al esqueleto postcraneal completo de una mujer joven $\left(\mathrm{n}^{\circ} 1\right)$; pero la existencia de fragmentos de un tercer fémur, ahora de una mujer adulta, revela la presencia en el depósito de restos de un segundo individuo $\left(\mathrm{n}^{\mathrm{o}} 2\right)$, e inclusive de un tercero, en este caso un subadulto, representado exclusivamente por un germen dentario. La explicación más plausible es que el primero fuera un enterramiento primario completo, pese a que del cráneo solo sobreviven los dientes, y que los huesos de 2 y 3 constituyeran elementos de acompañamiento (reliquias) introducidos deliberadamente en la fosa. Sin embargo, la escasez e irrelevancia de estos últimos confiere también verosimilitud a la opción de que $\mathrm{n}^{\circ} 1$ fuera un cadáver en proceso de descomposición detraído de un depósito colectivo y que, en el traslado a su nuevo destino, le acompañaran inadvertidamente y por puro azar el trozo de fémur y el diente embrionario de las otras dos personas. El reconocimiento en el esqueleto del enterramiento principal de manchas de coloración verde producidas por colonias de líquenes del género Lepraria, activas en contacto con la atmósfera, podría inclusive apoyar la sospecha de que todos ellos procedieran de un expositor o pudridero al aire libre (Caro Dobón et al., 1999), reforzando la idea - válida para cualquiera de los dos supuestos - de prácticas mortuorias en dos o más tiempos.

\section{Sepulturas provisionales, Casas de MUERTOS Y RELIQUIAS: UNA PROPUESTA SECUENCIA}

En resumen, más allá de las dudas que plantea el funcionamiento particular de cada yacimiento, se reconoce con la suficiente seguridad un fenómeno de movimiento de huesos que apoyarían igualmente otros hallazgos como la tibia inédita recuperada en uno de los fosos del recinto vallisoletano de El Casetón de la Era, en Villalba de los Alcores, o los numerosos restos depositados al pie del menhir burgalés de Piedra Alta, en San Pedro Samuel (Delibes et al., 2013: 45). Una situación ilustrativa de la existencia de prácticas mortuorias en dos tiempos o de "dobles exequias" a lo largo de las cuales, como se conoce bien entre los aborígenes de Indonesia, de Norteamérica y de otras muchas regiones del mundo, se suele seguir un plan complejo que dura meses o años. Este comienza tras la muerte biológica del individuo y comprende dos grandes etapas: las "primeras exequias", que Robert Hertz denominaba el "periodo intermedio", en las que al difunto se le proporcionaba asilo provisional entre los vivos, hasta que el cadáver se convertía en esqueleto y -por eliminación de sus humores pútridos- se neutralizaban sus malos espíritus; y, a continuación, la "ceremonia final", que comportaba la reinhumación de los huesos limpios en un nuevo locus, o en sucesivos loci, momento en que finalizaba el periodo de luto para los parientes y en que el muerto renacía socialmente, ya como antepasado (Hertz, 1990; Couderc, 2007). Sin duda un complejo ritual, asociado a la idea de que la muerte no era destrucción sino un cambio de estatus, que el jesuíta Joseph François Lafitau, tras una larga estancia como misionero entre los Iroqueses de Canadá a comienzos del siglo XVIII, resumía así: "En la mayor parte de las naciones salvajes los cuerpos muertos solo están en la sepul- 


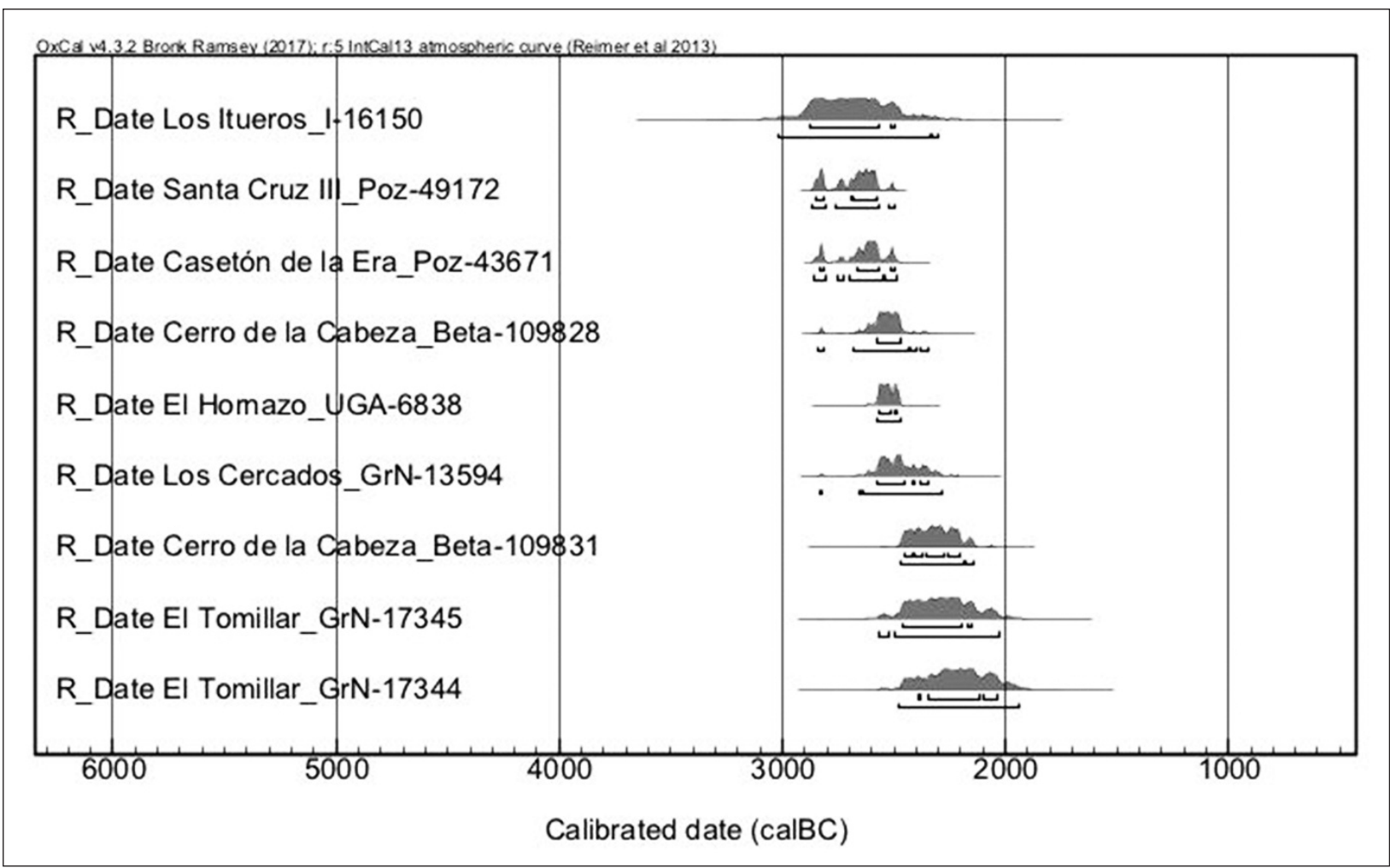

Figura 8. Fechas C-14 calibradas correspondientes a hoyos con huesos humanos aislados o con inhumaciones secundarias del Calcolítico Inicial del valle medio del Duero.

tura donde se los colocó en principio a modo de depósito, ya que después de cierto tiempo son objeto de nuevos funerales y se termina de cumplir con ellos por medio de nuevos deberes funerarios" (Lafitau, 1724: 444).

Aunque la Arqueología ha demostrado repetidamente su competencia para acreditar, desde diferentes ópticas, conductas de estas características en la Prehistoria Reciente del Viejo Mundo (Larsson, 2003; Brück, 2006: 80-85; Kólar, 2012; Booth y Madgwick, 2016), en nuestro caso topamos todavía con muchas dificultades a la hora de rastrear paso a paso la secuencia del mencionado ritual de las dobles exequias. Pero ello no impide que, a partir de los datos de que se dispone, creamos posible rastrear en diferentes yacimientos de la Cuenca del Duero las distintas fases que conformarían una secuencia de funerales dobles:

\subsection{La sepultura provisional}

pudridero o reapertura de tumbas primarias. Con respecto a la forma que pudo adoptar la sepultura provisional caben dos posibilidades, como hemos visto: que se tratara de un pudridero o de auténticas tumbas que sería necesario reabrir, situaciones ambas bien documentadas etnográfica- mente (Hertz, 1990: 21). No hemos comentado aún, al menos con el énfasis debido, que la imagen un tanto sofisticada que hasta aquí se ha ido desgranando del mundo funerario calcolítico del sector central de la Cuenca del Duero, con inhumaciones en fosa completas o parciales que se distribuyen sin demasiada regularidad por "campos de hoyos" y que seguramente, debido a su bajo número, no representan la auténtica norma funeraria, es la misma que se acredita en idéntico espacio durante la Edad del Bronce, lo que obliga a considerar la posibilidad de que represente el germen o punto de partida de una misma tradición que duró casi dos milenios. De ahí la pertinencia de recordar que en el yacimiento Cogotas I de Tordillos, en la localidad salmantina de Aldeaseca de la Frontera, se han documentado huellas incontrovertibles huesos roídos por carnívoros, representación esquelética parcial y contadas conexiones anatómicas, nunca lábiles - de que muchos de los cadáveres fueron depositados en los hoyos con los huesos limpios y desarticulados, después de haberse descarnado en un expositor subaéreo (Esparza et al., 2012b). Nuevos casos, actualmente en curso de publicación, en los yacimientos de Canto Blanco (Sahagún) y Cerro de la Cabeza (Ávila) vendrían a respaldarlo. 
Para el Calcolítico inicial no hay información tafonómica tan reveladora, salvo algún dato también de mordisqueos de perro en tumbas múltiples precampaniformes de la comunidad de Madrid (Liesau, 2017: 311). Pero las posturas de algunas inhumaciones son tan forzadas e inverosímiles - p.e. en el hoyo $n^{\circ} 3$ del Cerro de la Cabeza y en el n ${ }^{\circ} 5$ de Fuente Celada, éste en Burgos - que sus excavadores no dudan en afirmar que los cadáveres correspondientes tuvieron que ser introducidos en las fosas en estado de descomposición muy avanzado o momificados, ya sin músculos y con los ligamentos secos (Fabián y Blanco, 2012: 110; Carmona, 2013: 292). Otro posible argumento a favor de la exposición subaérea vendría dado por la ya comentada huella de Lepraria en los huesos de la fosa de Colmenares, ilustrativa de su exposición en algún momento, ya esqueletizado el cadáver, al aire. Y un último dato a valorar en la misma línea, aunque tampoco definitivo, sería la presencia, junto a inhumaciones relativamente completas, de huesos menudos de otros individuos, no en vano podrían interpretarse como piezas que, desde el expositor común, hubieran acompañado involuntaria e inadvertidamente a aquellas durante el traslado a su nuevo destino.

Pero esto no excluye por completo que los huesos de algunos depósitos secundarios pudieran proceder de la reapertura de fosas primarias, donde la esqueletización de los cadáveres se habría materializado no en régimen atmosférico sino subterráneo. En el modelo antropológico no se considera demasiado esta fórmula (Hertz, 1990: 20-21), pero es proceder común en el horizonte del vaso campaniforme de la Submeseta Sur donde existió la costumbre de reabrir viejas fosas de enterramiento a fin de introducir nuevos cadáveres, con la consecuencia de alterar las inhumaciones originales y de extraer de ellas algunas reliquias (Liesau, 2014: 141-142) ${ }^{8}$. En el Cobre inicial las pruebas de un comportamiento de este tipo son más raras, pero no por completo inexistentes: en la fosa múltiple del Cerro de la Cabeza a cuatro de las seis inhumaciones, todas de varones, les falta alguna pieza esquelética lo que en este caso, considerando los huesos afectados, no es atribuible ni a problemas de conservación diferencial ni a falta de rigor en la excavación (Fabián y Blanco, 2012: 102): el pie derecho completo al $n^{\circ} 1$; el extremo de una pierna, desde la rodilla, al $\mathrm{n}^{\circ} 2$; el húmero y parte de la mandíbula inferior al $\mathrm{n}^{\circ} 4$; y todos los huesos del tobillo al no 6 (Fabián y Blanco, 2012). En los dos primeros casos, la ausencia de los extremos de las piernas podría deberse a amputaciones, pero la explicación no es válida para los restantes, pues difícilmente pueden enterrarse brazos sin húmero o piernas con sus tibias y pies pero privadas de los huesos intermedios del tobillo. $\mathrm{Y}$, aunque no se pueda descartar, tampoco parece muy probable la hipótesis de Fabián y Blanco (2012: 102) de que tales ausencias se deban a mutilaciones realizadas antes del entierro de los cadáveres. Por tanto la explicación más razonable es que tales huesos fueran extraídos, tiempo después de practicada la inhumación, con fines necrolátricos o, con mucha más imaginación, como trofeos de guerra similares a los que exhibían los indios prehistóricos de California (Andrushko et al., 2009) ${ }^{9}$.

\subsection{La reunión en una sepultura definitiva: casa de muertos o túmulo colectivo}

La fase siguiente de los dobles funerales, que se celebra en una residencia temporal y que en la teoría antropológica se identifica con el largo velatorio y el servicio fúnebre que los familiares tienen la obligación de dispensar al muerto antes de ser enterrado para siempre - p.e. recogida reglada de los humores segregados en la putrefacción o lavado purificador de huesos - , apenas dejaría huella en el registro arqueológico, no así la ceremonia final en la que se procuraba una sepultura definitiva a los restos y se aseguraba, mediante una gran celebración o banquete, el acceso del alma del difunto al país de los muertos (Hertz, 1990: 57). Entre los aborígenes de Indonesia y Norteamérica esta residencia definitiva es normalmente colectiva, bien una "casa de muertos" en el propio poblado o un gran túmulo fuera de él; lo importante es que simbolice el reencuentro familiar y que propicie la reunión con los antepasados. ¿Cómo no recordar, llegados a este punto, que dos de nuestros yacimientos funerarios calcolíticos han sido objeto

\footnotetext{
8 Nada que ver, en principio, con los saqueos de tumbas para robar objetos de cobre, tan extendidos por entonces en Centroeuropa (Brun, 2007: 119).

9 A falta de un registro arqueológico exigente no nos decidimos a incluir en la relación de huesos detraídos de tumbas la mandíbula que falta en la inhumación correspondiente a una mujer de la fosa palentina de La Velilla, en Osorno (Delibes et al., e.p.).
} 
de una interpretación de este tipo? En la sepultura de Los Cardos, en Villayerno-Morquillas (Burgos), se describe una fosa múltiple con restos parciales de al menos 5 individuos, mayoritariamente huesos largos, que en su caso, por asociación con la idea del "Festín de la Muerte" de los Hurones/Wendat de Norteamérica - otra conocida variedad de enterramiento secundario-, se ha relacionado tanto o más con una ceremonia de integración política o alianza de comunidades distintas que con la necesidad normativa de reunir a los antepasados (Arnáiz et al., 1997). Y en una de las dos sepulturas múltiples de El Tomillar, en Bercial de Zapardiel (Ávila), que contiene los esqueletos incompletos de 11 individuos, se habla expresamente de "casa de muertos" y de un enterramiento secundario con restos "momificados parcialmente" que también habrían sido trasladados desde otros lugares (Fabián y Blanco, 2012: 116).

\subsection{El aprovechamiento de reliquias ancestrales}

Como reivindicábamos antes, la conducta acreditada en esos dos receptáculos múltiples, en un caso lleno de huesos secos seleccionados (Los Cardos) y en el otro de cadáveres momificados (El Tomillar), remite indiscutiblemente a una práctica de dobles funerales, lo mismo que la registrada en las fosas de Santa Cruz III y en tantas otras que no acogen grandes osarios sino huesos sueltos. Por encima de sus diferencias formales y conceptuales, ambas manifestaciones, el gran osario y el hueso aislado, son hijas de la tradición funeraria del enterramiento en dos tiempos. Entre algunos pueblos del Pacífico, como los Warramunga australianos, se opta por celebrar las exequias definitivas con un solo hueso en representación del todo, pero el paradero final de ese único hueso, por lo general un radio envuelto en una túnica, es innegociable y acaba inexorablemente en la tumba colectiva o morada de los antepasados (Hertz (1990: 58). Por tanto, en su caso se cumplen escrupulosamente las tres grandes etapas del ciclo y del rito de paso de las "dobles exequias", separación (muerte biológica), liminalidad (periodo transicional de luto y de cambio de estado) y reintegración (regreso del muerto a la comunidad, ya como antepasado), sin que la falta de integridad del esqueleto sea para ello un problema.

Frente a dicha situación, el aislamiento en que, como hemos venido viendo, comparecen los restos esqueléticos parciales en muchas de nuestras fosas podría dar a entender o bien que a los individuos correspondientes se les privó del normativo reen- cuentro familiar, o que, una vez convertidos en antepasados tras su paso por la "casa de muertos", esto es, sin dejar de participar en los "rituales de ancestría" (Barrett, 1989: 31), se procediera a retirar sus huesos de la morada común para su utilización en otro tipo de prácticas mortuorias. Obviamente, nos referimos en este caso a los fenómenos de circulación de reliquias o de "muertos en movimiento", como gráficamente los denominó Cauwe (1997), en los que los huesos de los antepasados, dotados de cualidades similares a los de los santos cristianos, desempeñan un papel crucial en un sinfín de ceremonias mágico-religiosas orientadas a reforzar el orden social y a construir memoria colectiva. Esta de las reliquias - cada vez mejor documentada en diversas áreas europeas, por ejemplo en las Islas Británicas, desde el Mesolítico a la Edad del Bronce (vid. Bradley, 1998: 53; Fowler 2004: 42, 74; Brück 2006: 80; Conneler, 2011: 362) - es, a nuestros ojos, la interpretación más razonable para los huesos aislados y depósitos parciales de nuestras fosas: que, en tanto restos de beneméritos ancestros, actuaran como elementos sancionadores y como garantes de compromiso intergrupal en la formalización de nuevas relaciones sociales (Brück, 2006; Kuijt, 2008; Blanco, 2011). La observación de Hertz (1990: 61), suscrita por Weiss-Krejci (2011: 75), de que el desmembramiento o la fragmentación de cuerpos para su conversión en reliquias se aplicaba sobre todo a jefes y personajes de alta consideración social - aquellos cuyos espíritus se creía de antemano menos dudosos a la hora de interceder por quienes conservaran e hicieran uso de sus restossería de enorme interés para el estudio arqueológico de los enterramientos parciales meseteños, pero a falta de ajuares personales y de ofrendas que permitan conocer la categoría social de los inhumados, tampoco es posible demostrar que dicho principio rigiera en nuestras fosas.

\subsection{Indicios de posibles celebraciones}

Finalmente, la teoría general sostiene que, como colofón de la "ceremonia final", ya depositados los huesos del difunto en la sepultura definitiva, se celebran grandes festejos públicos para asegurar el ascenso del alma a la estancia de los muertos y poner fin al largo periodo de luto de los deudos. Los testimonios etnográficos son, una vez más, enormemente expresivos y hablan de banquetes, de bebidas alcohólicas, de sacrificios de animales y humanos, de orgías y, en general, de gastos tan onerosos que nada raramente llevan a la ruina a las familias dolientes (Hertz, 1990: 55ss). 
En la supuesta "casa de muertos" de El Tomillar el acompañamiento arqueológico - escasos fragmentos de cerámica y fauna- no permite pensar en nada comparable, y tampoco en Los Cardos, aunque aquí se postula que, finalizada la deposición de los muertos y sometidos estos a un fuego purificador, se habrían ofrecido como presente colectivo tres cuencos completos de cerámica lisa que - añadimos nosotros como simple posibi- lidad - podrían haber sido utilizados en una libación de despedida. Pero, en rigor, la idea de la celebración de un gran festejo en cada reapertura de la morada de los antepasados no cuenta por el momento en nuestro caso con un refrendo arqueológico claro.

Sí podrían existir, por el contrario, indicios de "feasting" (sensu Dietler, 2012) en algunos de los hoyos con restos esqueléticos parciales, lo que

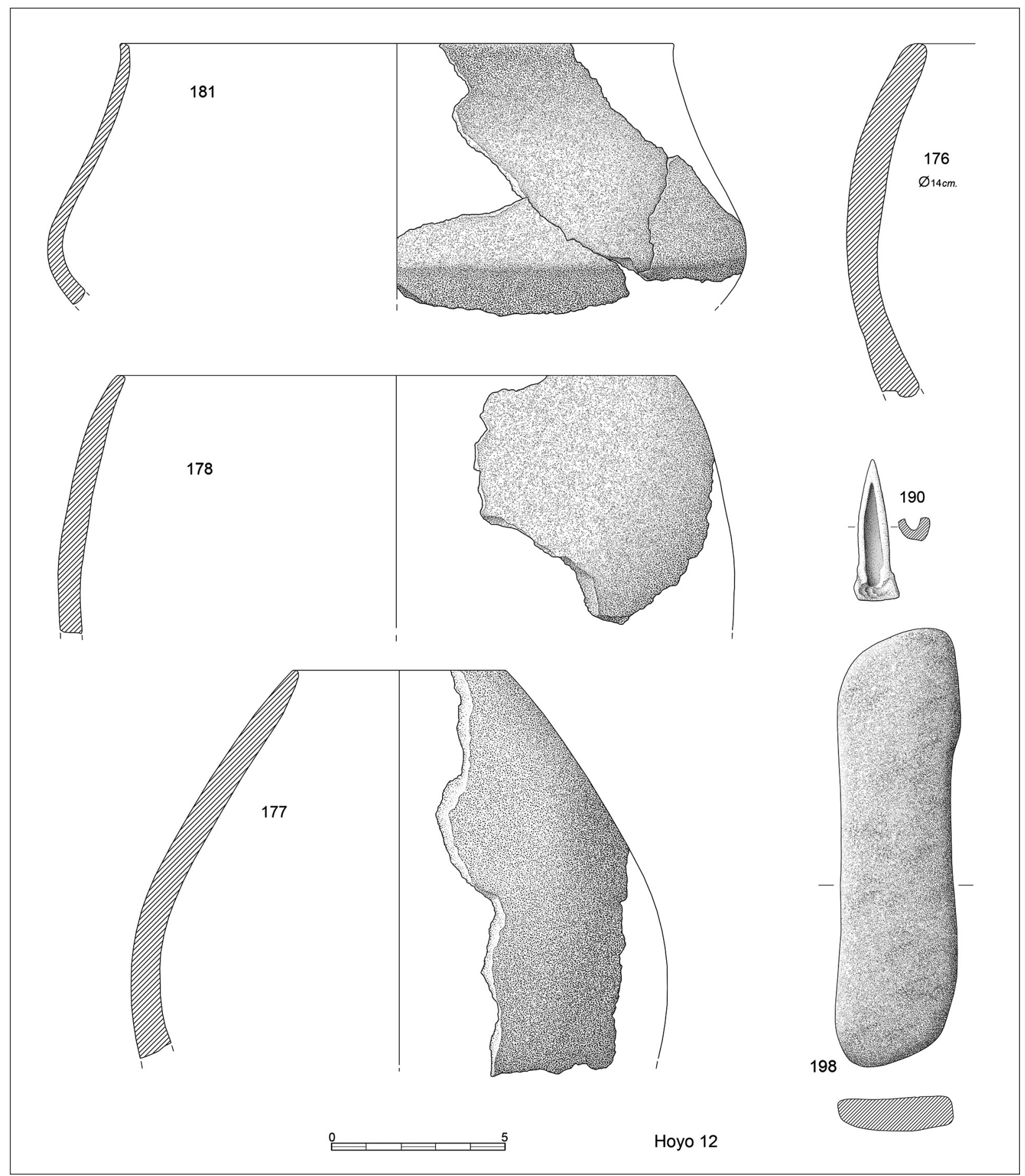

Figura 9. Materiales arqueológicos más representativos del hoyo $n^{\circ} 12$ de Santa Cruz III. 
reforzaría, por un lado, la idea de que no hay nada de accidental ni de aleatorio en dichos depósitos, y, por otro, la hipótesis de que se trata de reliquias comprometidas, por sus especiales propiedades, en actos sociales de alguna relevancia. Las evidencias consisten una vez más en acumulaciones de restos de cultura material y faunísticos, pero con un volumen fuera de lo común. En los hoyos 5 y 12 de Santa Cruz III con, como vimos, muy abundantes huesos de vacuno, de cabra/oveja, de cerdo, de perro ${ }^{10}$ y de ciervo, se recuperaron respectivamente 382 y 598 fragmentos de cerámica, además de varias decenas de piezas de sílex (entre ellas algunas herramientas) y de hueso (punzones y espátulas), lo que los sitúa, en cuanto a número de restos, en los puestos $7^{\circ}$ y $2^{\circ}$ de los 82 hoyos del yacimiento (figs. 9 y 10). En la fosa $103 \mathrm{del}$ Hornazo se repite la situación: mucha cerámica (319 piezas), aunque menos sílex (4) y restos de fauna (Carmona et al., 2013: 55-56). Y los datos de Los Cercados resultan abrumadores: casi 9000 elementos de cerámica (es cierto que en depósitos sucesivos) y extraordinaria abundancia de huesos de vaca, cerdo, ciervo y oveja, con el interesante complemento de otra serie de piezas vasos con decoración simbólica, una figurita de

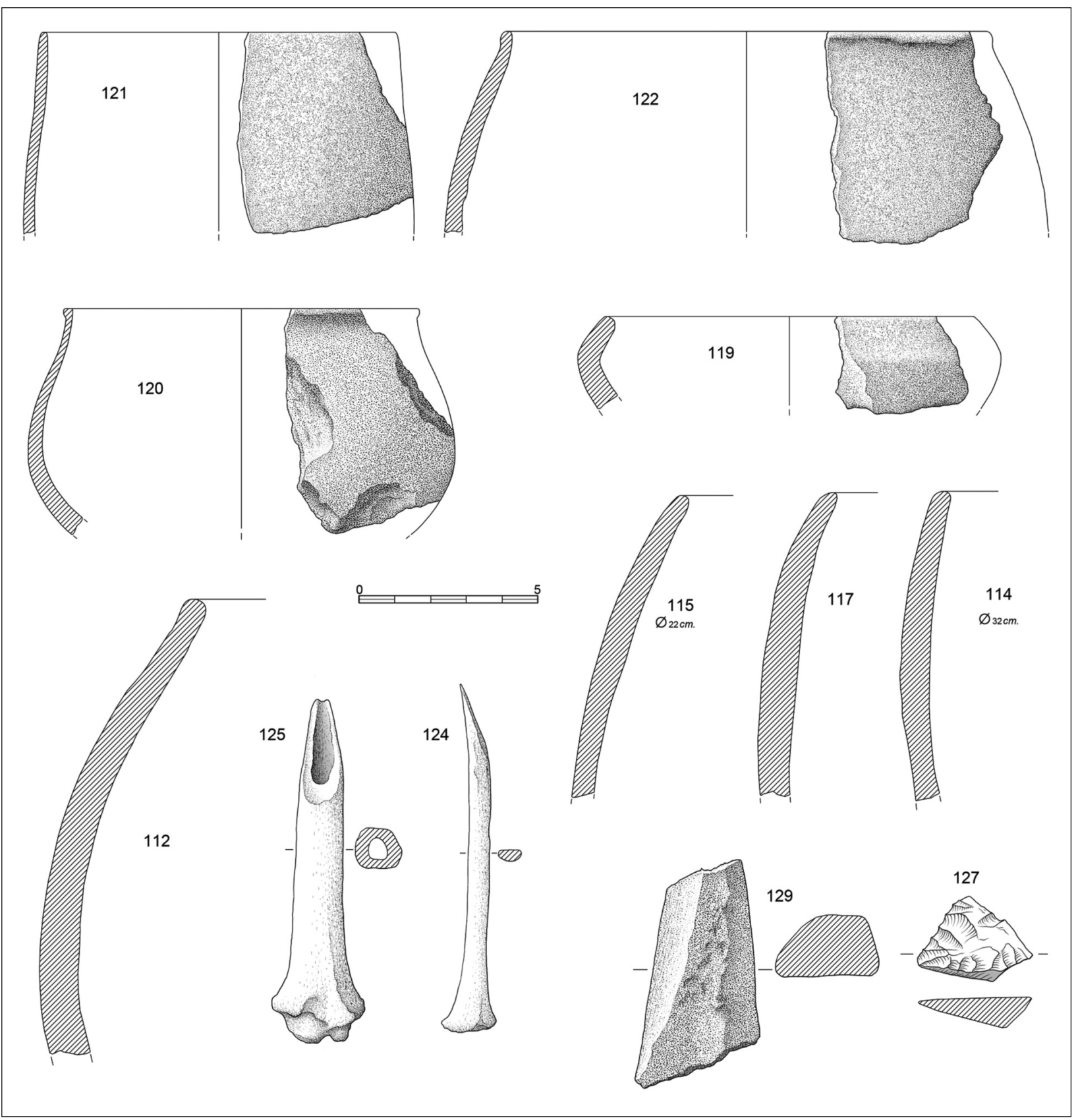

Figura 10. Materiales arqueológicos más representativos del hoyo $n^{o} 5$ de Santa Cruz III. 
barro - muy propias de ambientes ceremoniales. Evidentemente no son documentos tan resolutivos como aquellos en los que los restos funerarios se acompañan de vasijas completas o casi completas - además del caso mencionado de Los Cardos, la fosa 1 del Cerro de la Cabeza, la tumba de Colmenares, un singular enterramiento colectivo del Portalón, en Atapuerca (Pérez Romero et al., 2017; Delibes et al., e.p.) o, todavía más expresivo, un hoyo campaniforme de La Calzadilla, en Almenara de Adaja, en el interior de alguno de cuyos vasos se conservaban residuos de cerveza (Liesau et al., 2014) —, pero sin duda son muchas las posibilidades de que se trate, como se la denomina significativamente en ocasiones, de "basura ideologizada".

De todos estos yacimientos, el de Santa Cruz III es un "recinto de fosos", y según se dijo inicialmente es el único hasta ahora en la región duriense -con la duda de Los Cercados- en el que se ha documentado la presencia de enterramientos. Ello haría pensar de inmediato en el carácter ritual del lugar que - en una generalización prematura, ampliamente controvertida (vid. Thomas, 2016) se asigna a veces a estos recintos. Lo cierto es que en las excavaciones llevadas a cabo en Santa Cruz III se han documentado actividades domésticas y agropecuarias, pero no estructuras asignables a un ritual... en el sentido tradicional del término. Sin embargo, las inusuales acumulaciones de restos relacionables con actividades especiales pueden explicarse mejor si se contemplan como indicios de ritualizacion de la vida cotidiana, desde una perspectiva que, como preconizan Brück (1999) o Bradley (2003), no incurra en la reduccionista dicotomía entre práctico y ritual, entre profano y sagrado (Delibes et al., 2014: 188-189). La deposición de tan escogidos materiales - fauna selecta, sílex y punzones - a la vez que las reliquias humanas ¿no resultaría comprensible como el resultado de una práctica de ritualización de algún acontecimiento extraordinario de la vida de la comunidad del recinto, una ceremonia con consumo comunitario y el definitivo entierro de los huesos largamente conservados? ${ }^{11}$

\section{Consideraciones finales}

Los enterramientos parciales descubiertos en los hoyos 5 y 12 de Santa Cruz III, con paralelos en otros muchos yacimientos del sector central de la Submeseta Norte, acreditan la existencia de prácticas mortuorias secundarias entre las comunidades calcolíticas del sector central de la Submeseta Norte. Unas prácticas de "dobles funerales" o de "dobles exequias" que no parecen conceder demasiada importancia a la integridad de los cadáveres, pues los huesos, seleccionados y desarticulados, acostumbran a circular por el espacio de los vivos apareciendo bajo las viviendas, dentro de silos en áreas de almacenaje, en los rellenos de los fosos que circuyen los poblados, etc., todo ello en perfecta concordancia con la imagen de "muerte ubicua" captada en los "campos de hoyos" de esta época (Márquez, 2004). Sin embargo, el hecho de que tales enterramientos convivan con otras manifestaciones mortuorias (v.g. tumbas primarias) justifica la sospecha de que no representan el ritual funerario normativo de las poblaciones meseteñas de la Edad del Cobre. Nos hallamos con toda probabilidad, pues, ante solo una de las fórmulas seguidas en el tratamiento de los restos humanos, a cuyo conocimiento hemos querido contribuir buscando correspondencias entre la realidad de los documentos arqueológicos y las líneas maestras de una respetada teoría antropológica - la de Robert Hertz - sobre los enterramientos en dos tiempos.

La documentación arqueológica a la que nos referimos bien podría ser ilustrativa, en efecto, de algunas de las fases diferenciadas en los fenómenos de dobles exequias: descarnado y purificación de cadáveres en un expositor subaéreo; traslado de restos ya limpios a una "casa de muertos, con la idea de reintegrar socialmente al difunto como antepasado; interacción de los supervivientes con las reliquias de los ancestros, convertidas en poderosos instrumentos mnemotécnicos; $y$

\footnotetext{
${ }^{10}$ Como se indica a vuelapluma en la Memoria, no puede descartarse que hubiera dos canes relativamente completos, uno de ellos joven, repitiendo un gesto bastante habitual en contextos funerarios de esta época (Delibes et al. e.p.). Lamentablemente, como se ha indicado páginas atrás, no es posible confirmarlo por haberse entregado en el Museo de Valladolid solo una pequeña selección de los materiales recuperados en la excavación.

${ }^{11}$ En el Suroeste de la Península Ibérica, aunque se documenten dentro de los recintos de fosos algunos hoyos con restos esqueléticos parciales y en posición secundaria, es evidente que los auténticos cementerios, constituidos indistintamente por tholoi o hipogeos, se sitúan al margen aunque no lejos de tales yacimientos (Valera et al. 2016; Jiménez y Márquez, 2016). En Santa Cruz se repite la primera circunstancia -sólo hoyos con restos parciales- pero falta cualquier indicio sobre la posible existencia de una necrópolis normativa en sus inmediaciones.
} 
utilización de dichas reliquias en diversas ceremonias. Se trata, desde luego, de sólo una propuesta tentativa y aún con lagunas de tanto calado como calibrar el alcance de la exposición de cadáveres y la posibilidad de que fuese incluso la fórmula más común. Pero de la exposición hoy solo existen leves indicios y en su conocimiento - es preciso aceptarlo - solo será posible avanzar sustancialmente a partir de un replanteamiento teórico y metodológico de las excavaciones de espacios en los que se localicen restos humanos.

Pero, junto a debilidades tan ostensibles, también resplandecen algunas fortalezas como la probable identificación de las fosas colectivas de Los Cardos y de El Tomillar con "casas de muertos" o el reconocimiento de un fenómeno de circulación de reliquias del que, además de en los hoyos de Santa Cruz, existen pruebas en Los Cercados, en el Cerro de la Cabeza, en Colmenares, en El Hornazo, etc. Unas reliquias que no siempre se corresponden con las partes más representativas del esqueleto y que debieron de ser en general valiosas herramientas para crear memoria social a partir de los restos de los antepasados, aunque la primera intención al utilizarlas, como sugieren sus contextos, pudo haber sido distinta. En Colmenares, por ejemplo, la deposición de huesos de viejos parientes junto al cadáver reciente de una mujer dio ocasión a crear un poderoso símbolo comunitario, aunque su principal razón de ser fuera reivindicar la ascendencia mítica de la finada (Kuijt, 2008: 177). De los cráneos enterrados bajo sendas viviendas de Los Itueros y la Viña de Esteban García sería legítimo sospechar que fueran ofrendas de huesos ancestrales similares a las realizadas por las poblaciones prehispánicas de la costa de Perú en el transcurso de ritos fundacionales (Delibes Mateos, 2012: 375). Y a propósito de las cabezas de las mujeres inmoladas de Los Cercados nada tan razonable como recordar, dentro del solapamiento universalmente aceptado de cultos de la fecundidad y de cultos funerarios, aquellas arraigadas teorías que ven en el sacrificio una de las principales fuerzas fecundadoras de la muerte (Morin, 1970, 119-124). En todo caso, en relación con las reliquias o con estos hallazgos de huesos desmembrados es preciso destacar, por su transcendencia, dos detalles: Por una parte, que en su inmensa mayoría se localizan en áreas residenciales lo que, como recuerda Díaz del Río (2001: 292), denota una clara voluntad de que los antepasados sigan cohabitando con los vivos en el complejo doméstico. Y, por otra, que su deposición se acompañe de festejos comensales, de gran importancia para fomentar la solidaridad intergrupal (Dietler, 2012). De los depósitos con reliquias, en definitiva, parece posible afirmar que responden antes a un deseo de prolongar la actividad social de los ancestros que al de inmovilizar sus restos de forma irrevocable en una sepultura, algo que a los arqueólogos debería ponernos sobre aviso de la complejidad potencial de las biografías de los huesos humanos.

$\mathrm{Si}$, como señalábamos al principio del trabajo, la tradición investigadora siempre ha trazado una drástica frontera entre las costumbres funerarias megalíticas y las de la Edad del Cobre, la documentación en el Calcolítico de prácticas mortuorias secundarias podría constituir una invitación para cambiar de idea. Algunas diferencias, en todo caso, existen porque por lo general los dólmenes no fueron "casas de muertos" sino pudrideros correspondientes al primer tiempo de los “dobles funerales". Pero ello no es obstáculo para reconocer que el de las dobles exequias es un fenómeno muy antiguo, documentado desde el Mesolítico (Cauwe, 2001) y en la Península Ibérica, a juzgar por el testimonio de numerosas cuevas sepulcrales, firmemente implantado desde época neolítica (Weiss-Krejci, 2012b). En el polo opuesto, no es menor el interés de apreciar que la mayoría de los rasgos que caracterizan el mundo sepulcral calcolítico, enterramientos secundarios incluidos, se repiten sin grandes variaciones en el propio espacio de la Meseta y en el mismo tipo de yacimientos - los "campos de hoyos" - durante todo el segundo milenio cal a.C, lo que justifica cierta tendencia a hablar también de una misma tradición funeraria que abarcaría toda la Edad del Bronce, hasta el fin de Cogotas I (Esparza et al., 2012b).

En ese mismo sentido continuista, todavía se puede añadir otra observación. Porque, si bien es cierto que, al glosar las características de las sepulturas en hoyo, se apuntó que esos enterramientos primarios e individuales pudieran constituir un avance gradual de la individualidad, posible reflejo de una sociedad cada vez menos igualitaria, tal vez sería conveniente una posición más matizada. Sobre todo, porque las otras fórmulas mortuorias relacionadas con las dobles exequias permiten entrever la fuerza que todavía tienen las formas de "identidad relacional" - parentesco real o ficticio, pertenencia al grupo, a la comunidad, etc. - que eran también las vigentes en los osarios megalíticos y las que se mantendrán en Cogotas I: los lazos interpersonales eran conformados a través de la reutilización, circulación, exhibición y deposición de reliquias (Brück 2006). Probablemente 
irían también en la misma línea las hipotéticas celebraciones vinculadas a la sepultura definitiva: así, en la Fiesta de los Muertos de los Huron/Wendat y otras análogas se ha señalado (p.ej., Mezo, 2014) que, más allá del componente religioso, cobraba gran importancia lo social, pues "fortalecían sus lazos afectivos, creaban, renovaban o mantenían alianzas, y reafirmaban un sentido de identidad entre sus comunidades". De esta forma, concluimos, desde el Megalitismo a Cogotas I parece haber en lo social no poca continuidad, interrumpida apenas durante una etapa, la del Calcolítico Avanzado, con el fenómeno Campaniforme cuyas tumbas ponen claro acento en la individualidad - o en una versión distinta de la identidad relacional: la pertenencia a una élite (Hernando, 2002: 160-1)-, minando durante algún tiempo un orden milenario que frenaba la jerarquización (García García, 2017: 215ss).

\section{Agradecimientos}

Al Ministerio de Economía y Competitividad sin cuyo apoyo, a través de los proyectos del Plan Nacional i+D+i "Recursos, dieta y movilidad en las poblaciones del grupo Cogotas I" (HAR 201343851P) y "Nuevos hallazgos y nuevas perspectivas en el estudio de los restos humanos del Grupo Cogotas I" (HAR 2009-10105), no hubiéramos dispuesto de buena parte de la documentación analizada en el presente trabajo. A la Junta de Castilla y León por la concesión de los permisos preceptivos para llevar a cabo diversos análisis de los restos humanos de Santa Cruz III. A D ${ }^{a}$ Eloísa Wattenberg García y D. Fernando Pérez Rodríguez-Aragón por las molestias que les ocasionamos durante el estudio de los materiales en el Museo Provincial de Valladolid. Al Dr. Eduardo Carmona Ballestero, como responsable arqueológico del Servicio Territorial de Cultura de la Junta de Castilla y León de Valladolid, por facilitarnos la consulta de cuanta documentación sobre Santa Cruz III se conserva allí. Y a los dibujantes de la Universidad de Valladolid A. Rodríguez González y F. Tapias López por su contribución a la parte gráfica del trabajo.

\section{Bibliografía}

Aliaga Almela, R. (2008): "El mundo funerario calcolítico en la Región de Madrid". Cuadernos de Prehistoria y Arqueología de la Universidad Autónoma de Madrid, 34: 23-39. https://doi.org/10.15366/ cupauam2008.34.002.
Aliaga Almela, R. (2012): "Términos y conceptos para el estudio de las prácticas funerarias en Arqueología”. Historia Autónoma, 1: 13-20.

Andrés Rupérez, M. T. (1990): "Sepulturas calcolíticas de inhumación múltiple simultánea en la cuenca media del Ebro". Caesaraugusta, 66-67: 13-28.

Andrusko, V., Schwitalla, A. W. y Walker, Ph. (2009): "Trophy-taking and dismemberment as warfare strategies in prehistoric central California". American Fournal of Physical Anthropology, 141(1): 8396. https://doi.org/10.1002/ajpa.21117.

Arnáiz, M. A., Pascual, S. y Rojo, A. V. (1997): "Los semejantes y los otros: la sepultura múltiple simultánea de Villayerno-Morquillas, Burgos. Nota preliminar". BSAA, LXIII: 49-69.

Barrett, J. C. (1988): "The living, the dead and the ancestors. Neolithic and Bronze Age mortuary practices", en J. C. Barrett e I. A. Kinnes (eds): The Archaeology of context in the Neolithic and Bronze Age: recent trends, Department of Archaeology and Prehistory University of Sheffield. Sheffield: 30-41.

Blanco-González, A. (2011): "Práctica social, memoria y ritual en Cogotas I. Esbozo teórico para un enfoque renovado". Trabajos de Prehistoria, 68 (1): 123146.

Bocquentin, F., Chambon, P., Le Goff, I., Leclerc, J., Pariat, J. P., Pereira, G., Thevenet, G. y Valentin, F. (2010): "De la récurrence à la norme: interpréter les pratiques funéraires en préhistoire". Bulletins et Mémoires de la Société d'Anthropologie de Paris, 22: 157-171. https://doi.org/10.1007/s13219-010$0017-8$.

Booth, J. T. y Madgwick, R. (2016): "New evidence for diverse secondary burial practices in Iron Age: A histological case study". Fournal of Archaeological Science, 67: 14-24. https://doi.org/10.1016/ j.jas.2016.01.010.

Booth, J. T., Chamberlain, A. y Pearson, M. (2015): "Mummification in Bronze Age Britain". Antiquity, 89 (347): 1155-1173. https://doi.org/10.15184/ aqy.2015.111.

Bradley, R. (1998): The Significance of Monuments. On the shaping of human experience in Neolithic and Bronze Age Europe. Routledge. London.

Bradley, R. (2003): "A Life Less Ordinary: the Ritualization of the Domestic Sphere in Later Prehistoric Europe". Cambridge Archaeological Fournal, 13(1): 5-23. https://doi.org/10.1017/ S0959774303000015. 
Brück, J. (1999): "Ritual and rationality: some problems of interpretation in European archaeology". European Journal of Archaeology, 2(3): 313-344. https://doi.org/10.1179/eja.1999.2.3.313.

Brück, J. (2006): "Death, exchange and reproduction in the British Bronze Age". European Fournal of Archaeology 9, (1): 73-101, https://doi.org/10.1177 /1461957107077707.

Brun, P. (2004): "Réflexion sur la polysémie des pratiques funéraires protohistoriques en Europe", en L. Baray (dir.): Archéologie des pratiques funéraires. Approches critiques: Actes de la Table Ronde des 7 et 9 juin 2001, Glux-en-Glenne. Glux-en-Glenne. Centre Archéologique Européen. Bibracte: 55-64.

Brun, P. (2007): "Les pratiques funéraires de l'Age du Bronze: quel reflet sociologique?", en L. Baray, P. Brun y A. Testart (dirs.): Pratiques funéraires et sociétés: Nouvelles approches en archéologie et en anthropologie sociale: Actes du colloque interdisciplinaire de Sens 12-14 juin 2003. Eds. Universitaires de Dijon. Dijon: 115-132

Buikstra, J. y Ubelaker, D. (eds.) (1994): Standards for data collection from human skeletal remains. Proceedings of a Seminar at the Field Museum of Natural History. Arkansas Archeological Report Research Series 44. Fayetteville.

Campillo, D. y Subirá, M. E. (2004): Antropología fisica para arqueólogos. Ariel Prehistoria. Barcelona

Carmona Ballesteros, E. (2013): Calcolítico en la cuenca media del Arlanzón (Burgos, España): comunidades campesinas, procesos históricos y transformaciones. British Archaeological Reports, i.s. 2559, Archaeopress. Oxford.

Carmona Ballesteros, E., Valdivielso Gutiérrez, E., Pascual Blanco, S. y Vega y Miguel, J. J. (2013): "Restos humanos, contextos funerarios y diversidad formal. Los yacimientos calcolíticos de El Hornazo y El Túmulo IL.C1 de Cótar (Burgos)". Revista Atlántica-Mediterránea de Prehistoria y Arqueología Social, 15: 53-80. https://doi.org/ 10.25267/Rev_atl-mediterr_prehist_arqueol_ soc.2013.v15.04.

Cauwe, N. (1997): "Les morts en mouvement. Essai sur l'origine des rites funéraires mégalithiques", en A. A. Rodríguez Casal (ed.): O Neolítico Atlántico e as Orixes do Megalitismo. Actas do Coloquio Internacional (Santiago de Compostela, 1-6 abril de 1996). Cursos e Congresos da Universidade de Santiago de Compostela $\mathrm{n}^{\circ}$ 101. Santiago de Compostela: 719-737.
Cauwe, N. (2001): "Skeletons in motion, ancestors in action: Early mesolithic collective tombs in Southern Belgium". Cambridge Archaeological fournal, 11(2): 147-163. https://doi.org/10.1017/ S0959774301000087

Caro Dobón, L., Rodríguez Otero, H., Sánchez Compadre, E. y Prada Marcos, M. E. (1999): "Informe antropológico de los restos humanos hallados en el enterramiento en fosa de Colmenares en Arrabal de Portillo (Valladolid)". Estudos Pre-históricos, VII: 125-127.

Conneler, Ch. (2011). "The Mesolithic", en T. Insoll (ed.). The Oxford Handbook of the Archaeology of Ritual and Religion. Oxford University Press. Oxford: 358370 .

Couderc, P. (2007): "Les rites de la mort à Borneo: separation ou renaissance? Actualité de Robert Hertz". Reseña de W. D. Wilder (ed.): Journeys of the soul: Anthropological Studies of Death. Burial and Reburial Practices in Borneo. Borneo Research Council Monograph Series 7, Williamsburg, 2003 Moussons, 11: 211-224. Disponible en https://journals.openedition.org/moussons/1837

Delibes de Castro, G., Moreno Gallo, M., Villalobos García, R. y Basconcillos Arce, J. (2013): Piedra Alta. El guardián del páramo. Diputación de Burgos. Burgos.

Delibes de Castro, G. (2014): "El Calcolítico en la Meseta y su orla atlántica: Intensificación económica y avance de la vida sedentaria (3200-2500 cal. AC)", en M. Almagro Gorbea (ed.): Protohistoria de la Península Ibérica: del Neolítico a la Romanización. Universidad de Burgos-Fundación Atapuerca. Burgos: 95-112.

Delibes de Castro, G., Marcos García, M., Olmo Martín, J. de y Santiago Pardo, J. (2014): Los recintos de fosos calcolíticos del valle medio del Duero: Arqueología Aérea y Espacial. Studia Archaeologica $n^{\circ}$ 100, Secretariado de Publicaciones de la Universidad de Valladolid. Valladolid.

Delibes de Castro, G., Crespo Díez, M. y Rodríguez Marcos, J. A. (2016): "Anatomía de un recinto de fosos calcolítico del valle medio del Duero: El Casetón de la Era (Villalba de los Alcores, Valladolid)", en Del Neolític a l'Edat del bronze en el Mediterrani occidental. Estudis en homenatge a Bernat Martí Oliver. Trabajos Varios del SIP n ${ }^{\circ} 119$, Diputación de Valencia. Valencia: 387-401. 
Delibes de Castro, G., Esparza Arroyo, A., Velasco Vázquez, J., Zapatero Magdaleno, P., Palomo Díez, S., Fernández Rodríguez, C., Carbajo Arana, M., Palomo Díez, S. y Misiego Tejada, J. (e.p.): "Dos tumbas individuales calcolíticas en las inmediaciones de los dólmenes de Osorno y Simancas: Estudio bioantropológico, ofrenda de perros y afterlife megalítica en el valle medio del Duero", Trabajos de Prehistoria, 2018.

Delibes Mateos, R. (2012): Desenterrando tesoros en el siglo XVI. Compañias de huaca y participación indígena en Trujillo del Perú. CSIC-Universidad de SevillaDiputación de Sevilla. Sevilla.

Díaz del Rio, P. (2001): La formación del paisaje agrario. Madrid en el III y II milenios BC. Serie Arqueología. Paletnología y Etnología 9, Comunidad de Madrid. Madrid.

Díaz del Rio, P., Consuegra, S., Peña Chocarro, L., Márquez, B., Sampedro, C., Moreno, R., Albertini, D. y Pino, D. (1997): "Paisajes agrarios prehistóricos en la Meseta peninsular: el caso de Las Matillas (Alcalá de Henares, Madrid)". Trabajos de Prehistoria, 54 (2): 93-111, https:// doi.org/10.3989/tp.1997.v54.i2.368.

Dietler, M. (2012): "Feasting and fasting", en T. Insoll (ed.): The Oxford Handbook of the Archaeology of Ritual and Religion. Oxford University Press. Oxford: 179194. https://doi.org/10.1093/oxfordhb/ 9780199232444.013 .0014$.

Duday, H. (1990):"Observations ostéologiques et décomposition du cadavre: sépulture colmatée ou en espace vide". Revue Archéologique du Centre de la France, 29 (2): 193-196. https://doi.org/10.3406/ racf.1990.2634.

Duday, H., Cipriani, A. M., y Pearce, J. (2009). The archaeology of the dead: lectures in archaeothanatology. Studies in Funerary Archaeology 3, Oxbow Books. Oxford. https://doi.org/10.2307/ j.cttlcd0pkv.

Esparza Arroyo, A., Delibes de Castro, G., Velasco Vázquez, X. y Cruz Sánchez, P. J. (2008): "Historia de un golpe en la cabeza: sobre el enterramiento calcolítico del Hoyo 197 de "El Soto de Tovilla" (Tudela de Duero, Valladolid)". BSAA Arqueología, 74: 9-48.

Esparza Arroyo, A., Velasco Vázquez, J. y Delibes de Castro, G. (2012a): "HUM 2005-00139:
Planteamiento y primeros resultados de un proyecto de investigación sobre la muerte en Cogotas I", en J. A. Rodríguez Marcos y J. Fernández Manzano (eds.): Cogotas I: una cultura de la Edad del Bronce en la Península Ibérica. Serie Arte y Arqueología $n^{\circ} 30$, Universidad de Valladolid. Valladolid: 259-320

Esparza Arroyo, A., Velasco Vázquez, J. y Delibes de Castro, G. (2012b): "Exposición de cadáveres en el yacimiento de Tordillos (Aldeaseca de la Frontera, Salamanca). Perspectiva bioarqueológica y posibles implicaciones para el estudio del ritual funerario de Cogotas I". Zephyrus, 79: 95128.

Etxeberria Gabilondo, F. (1995): "Informe sobre los huesos humanos procedentes del enterramiento colectivo de "El Tomillar" (Bercial de Zapardiel, Ávila)", en J. F. Fabián: El aspecto funerario durante el Calcolítico y los inicios de la Edad del Bronce en la Meseta Norte. Acta Salmanticensia 93, Universidad de Salamanca. Salamanca: 45-58

Fabián García, J. F. (1995): El aspecto funerario durante el Calcolítico y los inicios de la Edad del Bronce en la Meseta Norte. Acta Salmanticensia 93, Universidad de Salamanca. Salamanca.

Fabián García, J. F. (2006): El IV y III Milenio AC en el Valle Amblés (Ávila), Col. Arqueología en Castilla y León 5, Junta de Castilla y León. Salamanca.

Fabián García, J. F. y Blanco González, A. (2012): "Cuatro enterramientos calcolíticos en hoyo del Cerro de la Cabeza (Ávila)". Complutum, 23 (1): 99120. https://doi.org/10.5209/rev_CMPL. 2012.v23.n1.39533.

Fernández Crespo, T. y de la Rúa, C. (2015): "Demographic evidence of selective burial in megalithic graves of northern Spain". Journal of Archaeological Sciences, 53: 804-617. Fowler, C. (2004). The Archaeology of Personhood. An Anthropological Approach. Routledge, London. https://doi.org/10.1016/j.jas.2014.11.015.

García Barrios, A. S. (2006): Los inicios de la Edad del Cobre en el valle medio del Duero: una aproximación a los modos de vida en el centro de la Meseta en los albores de la metalurgia. Universidad de Valladolid. Valladolid.

García Barrios, A. S. (2007): "Un enfoque de género en la arqueología de la prehistoria reciente del valle medio del Duero: los cráneos femeninos calcolíti- 
cos de Los Cercados (Mucientes, Valladolid)", en C. de la Rosa, M. J. Dueñas, M. I. del Val y M. Santo Tomás (coords.): Nuevos enfoques para la enseñanza de la historia. Mujer y género ante el espacio europeo de educación superior. Asociación Cultural AlMudayna. Madrid: 41-56.

García García, M. (2017): La Edad de los Metales en el Duero medio: la evolución del paisaje y de las sociedades. Studia Archaeologica $n^{\circ} 102$, Secretariado de Publicaciones de la Universidad de Valladolid, Valladolid.

Hernando Gonzalo, A. (2002): Arqueología de la identidad. Akal. Torrejón de Ardoz.

Herrán Martínez, J. I. y Rojo Guerra, M. A. (1999): “¿Una nueva tumba en fosa calcolítica? El hallazgo de Colmenares, Portillo (Valladolid, España), y su contexto arqueológico". Estudos Pre-historicos VII: 111-124.

Hertz, R. (1907): "Contribution à une étude sur la représentation collective de la mort". Année Sociologique, 10: 48-137.

Hertz, R. (1990): La muerte y la mano derecha, Alianza Universidad 637, Alianza Editorial. Madrid (1 ${ }^{\mathrm{a}}$ Ed. de 1909).

Hughes, E. A. (2014): Structured depositions and the interpretation of ritual in the Near East Neolithic: a new methodo$\log y$. University of Liverpool. Disponible en https://livrepository.liverpool.ac.uk/17513/1/H ughesEri_April2014_17513.

Jiménez Jaimez, V. y Márquez Romero, J. E. (2016): "Prehistoric ditched enclosures and necropolises in Southern Iberia: a diachronic overview", en V. Ard y L. Pillot (eds.): Giants in the Landscape: monumentality and territories in the European Neolithic, Proceedings of the XVII UISPP World Congress, Burgos, Spain, vol. 3, Session A25. Archaeopress. Oxford: 57-68.

Kolár, J. (2012): "Secondary mortuary practices during the Late Eneolithic in Moravia, Czech Republic: State of knowledge, history of research, terminology and interpretations", en J. Kolár y F. Trampota (eds.): Theoretical and methodological Considerations in Central European Neolithic Archaeology. British Archaeological Reports. International Series 2325. Archaeopress. Oxford: 25-44.

Kuijt, I. (2008): "The regeneration of life. Neolithic structures of symbolic remembering and forget- ting". Current Anthropology, 49(2): 171-197, https://doi.org/10.1086/526097.

Lafitau, J. F. (1724): Moeurs des sauvages amériquains comparées aux moeurs des premiers temps. Tome Second. Saugrain y Estiennes de Hocherau. Paris. Disponible en: https://gallica.bnf.fr/ark:/ 12148/btv1b86029431/f9.image

Larsson, A. M. (2003): "Secondary burial practices in the Middle Neolithic". Current Swedish Archaeology, 11: 153-170.

Liesau von Lettow Vorbeck, C., Rios, P., Vega, J., Menduiña, R. y Blasco, C. (2014): "Buscando los ancestros: La manipulación de los restos de las tumbas campaniformes en Camino de Las Yeseras (San Fernando de Henares, Madrid)", en M. Domingo y F. J. Pastor (coords.): Actas de las novenas jornadas de Patrimonio Arqueológico en la Comunidad de Madrid. Comunidad de Madrid. Madrid: 137-148.

Liesau von Lettow Vorbeck, C. (2017): "Campaniforme y Ciempozuelos en la región de Madrid”, en V. S. Gonçalves (coord.): Sinos e Taças. Junto ao oceano e mais longe: aspectos da presença campaniforme na Peninsula Ibérica, Estudos e Memorias UNIARQ 10. Lisboa: 302-323.

Liesau von Lettow Vorbeck, C., Guerra Doce, E. y Delibes de Castro, G. (2014): "Casual or ritual: "The Bell Beaker deposit of La Calzadilla (Valladolid, Spain)", Quaternary International, 330: 88-96. https://doi.org/10.1016/j.quaint.2013. 10.046 .

Márquez Romero, J. E. (2004): "Muerte ubicua: sobre la deposición de esqueletos humanos en zanjas y pozos en la prehistoria reciente de Andalucía", Mainake, XXVI: 115-138.

Metcalf, P. (1981): "Meaning and Materialism: The ritual economy of death". Man 16: 563-578. https://doi.org/10.2307/2801488.

Mezo González, J. C. (2014): "La Fiesta de los Muertos: Identidad, memoria y tradición entre los indios hurones a comienzos del siglo XVII". En: P. A. Fogelman y M. F. Contardo (Eds.): Actas electrónicas del V SIRCP: Quinto Simposio Internacional sobre Religiosidad, Cultura y Poder. Ediciones del GERE. Buenos Aires.

Moore, H. (1982): "The interpretation of spatial patterning in settlement residues", en I. Hodder (ed.): 
Symbolic and Structural Archaeology. Cambridge University Press. Cambridge: 74-79, https:// doi.org/10.1017/CBO9780511558252.008.

Moragón Martínez, L. (2012): "El cuerpo y la persona, una propuesta arqueo-lógica”. Revista Arkeogatze, 2: 21-32.

Morin, E. (1970): El hombre y la muerte. Kairós. Barcelona.

O’Shea,J. M. (1984): Mortuary variability. An archaeological investigation. Academic Press, Orlando.

Palomo Díez, S. (2015): Caracterización genética de las poblaciones de las Edades del Cobre y del Bronce de la Submeseta Norte de la Peninsula Ibérica. Tesis Doctoral, Universidad Complutense. Disponible en: eprints.ucm.es/34256/.

Palomo Díez, S., Esparza Arroyo, A., Gomes, C., Rickards, O., Velasco Vázquez, J., López-Parra, A. M., Baeza Richer, C., Martínez Labarga, G. y Arroyo Pardo, E. (2017): "Genetic characterization and determination of the number of individuals by molecular analysis in a prehistoric finding". Forensic Science International: Genetics Supplement Series 6: 487-489, https://doi.org/10.1016/ j.fsigss.2017.09.187.

Parker Pearson, M., Chamberlain, A., Craig, O., Marshall, P., Mulville, J., Smith, C., Chenery, G., Collins, M., Cook, G., Craig, G., Evans, J., Hiller, J., Montgomery, J., Schwenninger, J. L., Taylor, G. y Wess, T. (2005) "Evidence for mummification in Bronze Age Britain". Antiquity, 79: 529-546. https://doi.org/10.1017/S0003598X 00114486 .

Pérez-Romero, A., Iriarte, E., Galindo-Pellicena, M. A., García-González, R., Rodríguez, L., Castilla, M., Francés-Negro, M., Santos, E., Valdiosera, C., Arsuaga, J. L., Alday, A. y Carretero, J. M. (2017): “An unusual pre-bell beaker Copper Age cave burial context from El Portalón de Cueva Mayor site (Sierra de Atapuerca, Burgos)". Quaternary International, 433: 142-155, https://doi.org/10.1016/j.quaint.2015.06.063.

Robb, J. (2013): "Creating death and archeology of dying", en S. Tarlow y L. Nilsson Stutz (eds.): The Oxford Handbook of the Archaeology of Death and Burial. Oxford University Press. Oxford: 441-447.
Sánchez Polo, A. (2012): "Depósitos de cerámicas, molinos y elementos de hoz: una propuesta de la Edad del Bronce del interior peninsular desde la arqueología posprocesual”. Arqueogatze, 2: 73-93, https://doi.org/10.4995/var.2011.4620.

Santonja Gómez, M (1997): "Los tiempos prehistóricos", en M. Salinas y J. L. Martín (eds.): Historia de Salamanca. I. Prehistoria e Historia Antigua. Centro de Estudios Salmantinos. Salamanca: 17-122.

Sellier, P. (1996): "La mise en évidence d'anomalies démographiques et leur interprétation: Population, recrutement et pratiques funéraires du tumulus de Courtesoult", en J. F. Piningre (dir.): Nécropoles et Société Au Premier Âge du Fer: Le Tumulus de Courtesoult (Haute-Saône). Maison des Sciences de l'Homme (dAF) 54. Paris: 188-202.

Smith, M. J., Allen, M. J., Delbarre, G., Booth, T., Cheetham, P., Bailey, L., O’Malley, F., Parker Pearson, M. y Green, M. (2016): "Holding on to the past: Southern British evidence for mummification and retention of the dead in the Chalcolithic and Bronze Age". Journal of Archaeological Science: reports 10: 744-756, https://doi.org/10.1016/j.jasrep.2016.05.034.

Thomas, J. (2016): “Cattle, consumption and causewayed enclosures (response to Parmenter, Johnson and Outram)". World Archaeology 48(5): 729-744, https: / / doi.org/10.1080/00438243.2016. 1229214

Ubelaker, D. (2007): Enterramientos humanos. Excavación, análisis, interpretación. Munibe Suplemento 24, Sociedad de Ciencias Aranzadi. San Sebastián.

Valera, A. C. (2016): "Ditched enclosures and the ideologies of death in the Late Neolithic and Chalcolithic South Portugal", en V. Ard y L. Pillot (eds.): Giants in the Landscape: monumentality and territories in the European Neolithic, [Proceedings of the XVII UISPP World Congress, Burgos, Spain, vol. 3, Session A25. Archaeopress. Oxford: 69-84.

Van Gennep, A. (2013): Los ritos de paso. Alianza Editorial. Madrid (trad. esp. de Les rites de passage, E. Nourry, Paris, 1909).

Villalobos García, R. (2016a): Análisis de las transformaciones sociales de la Prehistoria Reciente de la Meseta Norte española (milenios VI-III cal. A.C.). Studia Archaeologica 101, Universidad de Valladolid. Valladolid. 
Villalobos García, R. (2016b): "Una aproximación cuantitativa al trabajo destinado a la arquitectura monumental en la Prehistoria reciente de la Meseta Norte española". Spal 25: 43-66, https://doi.org/10.12795/spal.2016i25.02.

Waldron, T. (2008): Palaeopathology. Cambridge University Press. Cambridge, https://doi.org/ 10.1017/CBO9780511812569.

Weiss-Krejci, E. (2011): "The formation of mortuary deposits: implications for understanding mortuary behavior of past populations", en S. C. Agarwal y B. Glencross (eds.): Social Bioarchaeology. Wiley and Blackwell. New York: 68-106, https://doi.org/ 10.1002/9781444390537.ch4.
Weiss-Krejci, E. (2012a): "The unburied dead", en S. Tarlow y L. Nilsson Stutz (eds.): The Oxford Handbook of the Archaeology of Death and Burial. Oxford University Press. Oxford: 281-301.

Weiss-Krejci, E. (2012b): "Shedding light on dark places. Deposition of the dead in cave-like features in Neolithic and Copper Age Iberia", en K. A. Bergsvik y R. Skeates (eds.): Caves in Context: The Cultural Significance of Caves and Rockshelters in Europe. Oxbow Books. Oxford: 118-137, https://doi.org/ 10.2307/j.ctvhldjk4.13.

Wilder, W. D. (2003): Fourneys of the soul: Anthropological studies of death burial and reburial practices in Borneo. Borneo Research Council. Williamsburg. 